\title{
Redox regulation of the Calvin-Benson cycle: something old, something new
}

\section{Laure Michelet ${ }^{1}$, Mirko Zaffagnini ${ }^{2}$, Samuel Morisse ${ }^{1}$, Francesca Sparla ${ }^{2}$, María Esther Pérez-Pérez ${ }^{1}$, Francesco Francia ${ }^{2}$, Antoine Danon ${ }^{1}$, Christophe H. Marchand ${ }^{1}$, Simona Fermani ${ }^{3}$, Paolo Trost ${ }^{2 *}$ and Stéphane D. Lemaire ${ }^{1 *}$}

${ }^{1}$ Laboratoire de Biologie Moléculaire et Cellulaire des Eucaryotes, FRE3354 Centre National de la Recherche Scientifique, Institut de Biologie Physico-Chimique, Université Pierre et Marie Curie, Paris, France

${ }^{2}$ Laboratory of Plant Redox Biology, Department of Pharmacy and Biotechnology (FaBiT), University of Bologna, Bologna, Italy

${ }^{3}$ Department of Chemistry "G. Ciamician," University of Bologna, Bologna, Italy

\section{Edited by:}

Nicolas Rouhier, Université de

Lorraine, France

\section{Reviewed by:}

Renate Scheibe, University of

Osnabrueck, Germany

David B. Knaff, Texas Tech

University, USA

*Correspondence:

Paolo Trost, Laboratory of Plant Redox Biology, Department of

Pharmacy and Biotechnology (FaBiT), University of Bologna, Via Irnerio 42, 40126 Bologna, Italy e-mail:paolo.trost@unibo.it;

Stéphane D. Lemaire, Laboratoire de Biologie Moléculaire et Cellulaire des Eucaryotes, FRE3354 Centre National de la Recherche Scientifique, Institut de Biologie

Physico-Chimique, Université Pierre et Marie Curie, 13 rue Pierre et

Marie Curie, 75005 Paris, France e-mail: stephane.lemaire@ibpc.fr
Reversible redox post-translational modifications such as oxido-reduction of disulfide bonds, S-nitrosylation, and S-glutathionylation, play a prominent role in the regulation of cell metabolism and signaling in all organisms. These modifications are mainly controlled by members of the thioredoxin and glutaredoxin families. Early studies in photosynthetic organisms have identified the Calvin-Benson cycle, the photosynthetic pathway responsible for carbon assimilation, as a redox regulated process. Indeed, 4 out of 11 enzymes of the cycle were shown to have a low activity in the dark and to be activated in the light through thioredoxin-dependent reduction of regulatory disulfide bonds. The underlying molecular mechanisms were extensively studied at the biochemical and structural level. Unexpectedly, recent biochemical and proteomic studies have suggested that all enzymes of the cycle and several associated regulatory proteins may undergo redox regulation through multiple redox post-translational modifications including glutathionylation and nitrosylation. The aim of this review is to detail the well-established mechanisms of redox regulation of Calvin-Benson cycle enzymes as well as the most recent reports indicating that this pathway is tightly controlled by multiple interconnected redox post-translational modifications. This redox control is likely allowing fine tuning of the Calvin-Benson cycle required for adaptation to varying environmental conditions, especially during responses to biotic and abiotic stresses.

\footnotetext{
Keywords: Calvin-Benson cycle,
} photosynthesis, redox regulation
$\mathrm{CO}_{2}$ fixation, thioredoxin, glutaredoxin, glutathionylation, nitrosylation, and cyanobacteria (Figure 1). In the 60s, the activity of several enzymes of the CBC was found to be regulated by light. These enzymes were found to have a low activity in the dark and to be activated in the light. Investigation of the molecular mechanism of this light-dependent regulation led to the identification of the ferredoxin/thioredoxin (Fd/TRX) system that plays a crucial role in numerous redox- and light-dependent reactions in chloroplasts. Four enzymes of the $\mathrm{CBC}$ regulated by light were shown to contain a regulatory disulfide oxidized in the dark and reduced in the light by TRX. This reduction allows transition from a low active form to a fully active enzyme. Additional proteins were also recognized as TRX-regulated targets such as proteins involved indirectly in the regulation of the $\mathrm{CBC}$, in light-dependent ATP production or in diverse carbon metabolism pathways (Lemaire et al., 2007; Schürmann and Buchanan, 2008). All these enzymes are regulated by light through TRX-dependent reduction of disulfide bonds. The mechanisms of this light-dependent regulation of carbon assimilation enzymes are considered as the best characterized mechanisms of redox signaling in photosynthetic organisms (Foyer and Noctor, 2005) since they were investigated in detail at the molecular and structural level in different model systems. 


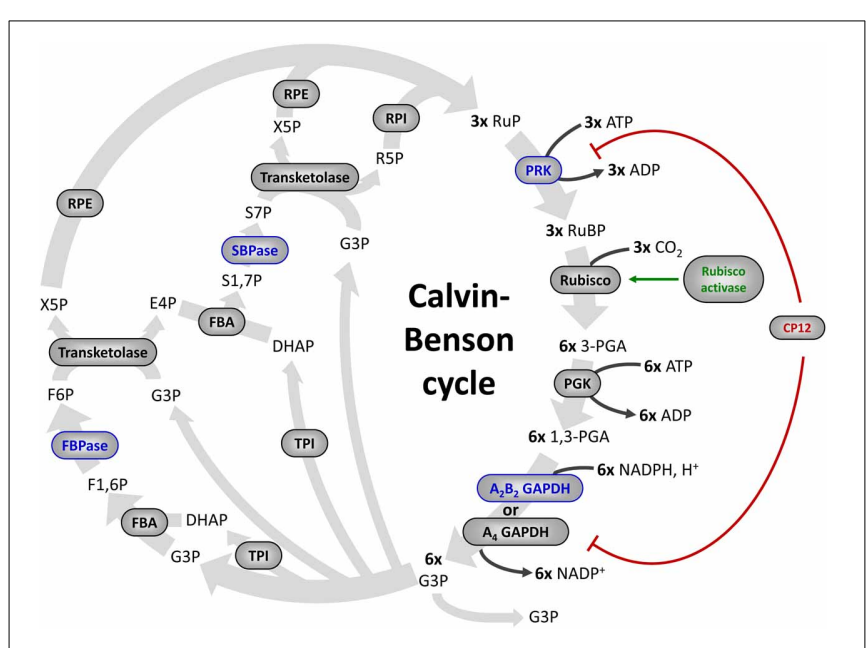

FIGURE 1 | The Calvin-Benson cycle. The eleven enzymes of the Calvin-Benson cycle are indicated in gray ellipses. Four enzymes (in blue) are activated directly by TRXs. Some proteins that control the activity of Calvin-Benson cycle enzymes are also regulated by TRXs: Rubisco activase (in green), and CP12 (in red), which forms a complex with PRK and $\mathrm{A}_{4}-\mathrm{GAPDH}$ and inhibits both enzymes. Enzymes: Rubisco,

ribulose-1,5-bisphosphate Carboxylase/Oxygenase; PGK, phosphoglycerate kinase; GAPDH, glyceraldehyde-3-phosphate dehydrogenase; TPI, triose phosphate isomerase; FBA, fructose-1,6-bisphosphate aldolase; FBPase, fructose-1,6-bisphosphatase; TK, transketolase; SBPase,

sedoheptulose-1,7-bisphosphatase; RPE, ribulose-5-phosphate

3-epimerase; RPI, ribose-5-phosphate isomerase; PRK,

phosphoribulokinase. Metabolites, RuBP, ribulose-1,5-bisphosphate; 3-PGA,

3-phosphoglycerate; 1,3-PGA, 1,3-bisphosphoglycerate; G3P,

glyceraldehyde-3-phosphate; DHAP, dihydroxyacetone phosphate; F1,6P,

fructose-1,6-bisphosphate; F6P, fructose-6-phosphate; X5P,

xylulose-5-phosphate; E4P, erythrose-4-phosphate; S1,7P,

sedoheptulose-1,7-bisphosphate; S7P, sedoheptulose-7-phosphate; R5P, ribulose-5-phosphate; RuP, ribulose-5-phosphate.

However, recent proteomic studies are now challenging this rather simple view. Indeed, proteomic analyses aimed at identifying new TRX targets suggested that not only four but all CBC enzymes might be redox-regulated through mechanisms likely involving cysteine residues (Lemaire et al., 2007; Lindahl et al., 2011). Moreover, all enzymes of the cycle were also identified by proteomic approaches as potential targets of nitrosylation and glutathionylation, two redox PTMs whose importance in signaling and regulation has emerged recently (Zaffagnini et al., 2012a). This suggests that the CBC is likely regulated by a complex network of interconnected redox PTMs that remain to be characterized. In this review we will provide an overview of our current knowledge on the redox regulation of CBC enzymes and related proteins and discuss the potential importance of novel types of redox modifications on our understanding of the regulation of $\mathrm{CO}_{2}$ fixation in photosynthetic organisms.

\section{THE FERREDOXIN/THIOREDOXIN SYSTEM}

During the $60 \mathrm{~s}$ and 70 s numerous studies have reported that the activity of four $\mathrm{CBC}$ enzymes was regulated by light (reviewed in Buchanan, 1980, 1991; Schürmann and Jacquot, 2000; Lemaire et al., 2007; Schürmann and Buchanan, 2008; Buchanan et al., 2012). These enzymes were phosphoribulokinase
(PRK), glyceraldehyde-3-phosphate dehydrogenase (GAPDH), fructose-1,6-bisphosphatase (FBPase), and sedoheptulose-1,7bisphosphatase (SBPase) (Figure 1). These four enzymes were found to have a low activity in the dark and to be activated under illumination. During the same period, a similar regulation was reported for NADP-malate dehydrogenase (NADP$\mathrm{MDH}$ ) (Johnson and Hatch, 1970) and chloroplast ATP synthase (McKinney et al., 1978, 1979). NADP-MDH is involved in $\mathrm{CO}_{2}$ fixation in $\mathrm{C} 4$ plants and in the export of excess reducing power from the chloroplast in $\mathrm{C} 3$ plants while chloroplast ATP synthase produces ATP equivalents required for $\mathrm{CO}_{2}$ fixation by the $\mathrm{CBC}$. The analysis of the molecular mechanisms underlying these lightdependent activations were mostly performed in the laboratory of Prof. Bob Buchanan in Berkeley and led to the identification of the so-called ferredoxin/thioredoxin system (Buchanan, 1991; Buchanan et al., 2002b). This system is composed of three types of chloroplast soluble proteins located in the stroma: ferredoxin (Fd), ferredoxin/thioredoxin reductase (FTR) and thioredoxin (TRX) (Figure 2). Upon illumination, ferredoxin is reduced by the photosynthetic electron transfer chain at the level of photosystem I (PSI). Chloroplastic Fd is located at a metabolic crossroad in the chloroplast and once reduced can transfer its electron(s) to enzymes involved in diverse metabolic pathways including photoreduction of NADP through ferredoxin/NADP reductase (FNR), reduction of sulfites and nitrites, lipid biosynthesis, hydrogen production (Winkler et al., 2010) and photosynthetic cyclic electron flow via ferredoxin-plastoquinone reductase (Hertle et al., 2013). Several isoforms of PSI-reduced Fd are present in photosynthetic organisms: 4 distinct Fd were described in the land plant Arabidopsis thaliana whereas 6 isoforms were reported in the green alga Chlamydomonas reinhardtii. These Fds are not equivalent as they exhibit some specificities toward their target enzymes and distinct expression profiles (Hanke et al., 2004; Terauchi et al., 2009). Under optimal growth conditions, most of the electron flux is likely directed to FNR to produce, in the form of NADPH, the reducing power required for $\mathrm{CO}_{2}$ fixation by the CBC. Part of the reduced Fd pool also transfers electrons to FTR which can subsequently reduce the disulfide bond present in the active site of several types of chloroplastic TRXs. FTR is a thin and flat $[4 \mathrm{Fe}-4 \mathrm{~S}]$ enzyme interacting with Fd on one side and TRX on the other side (Dai et al., 2007). A first Fd molecule binds FTR and transfers one electron to the FTR [4Fe-4S] cluster. An intermediate is then formed in which one sulfur atom of FTR active site is free to attack the disulfide of TRX and the other sulfur atom forms a fifth ligand for an iron atom in the FTR [4Fe-4S] center. A second Fd molecule then delivers a second electron that cleaves the FTR-TRX mixed-disulfide. FTR is therefore unique in its use of a $[4 \mathrm{Fe}-4 \mathrm{~S}]$ cluster and a proximal disulfide bridge in the conversion of a light signal into a thiol signal (Dai et al., 2007). Once reduced, TRXs are able to reduce regulatory disulfides on their target enzymes, including PRK, GAPDH, FBPase, and SBPase, allowing their activation upon illumination through reduction of their regulatory disulfide by the Fd/TRX system (Figure 3).

Originally identified for their ability to activate enzymes of the CBC, TRXs were later found to contribute to the regulation of 


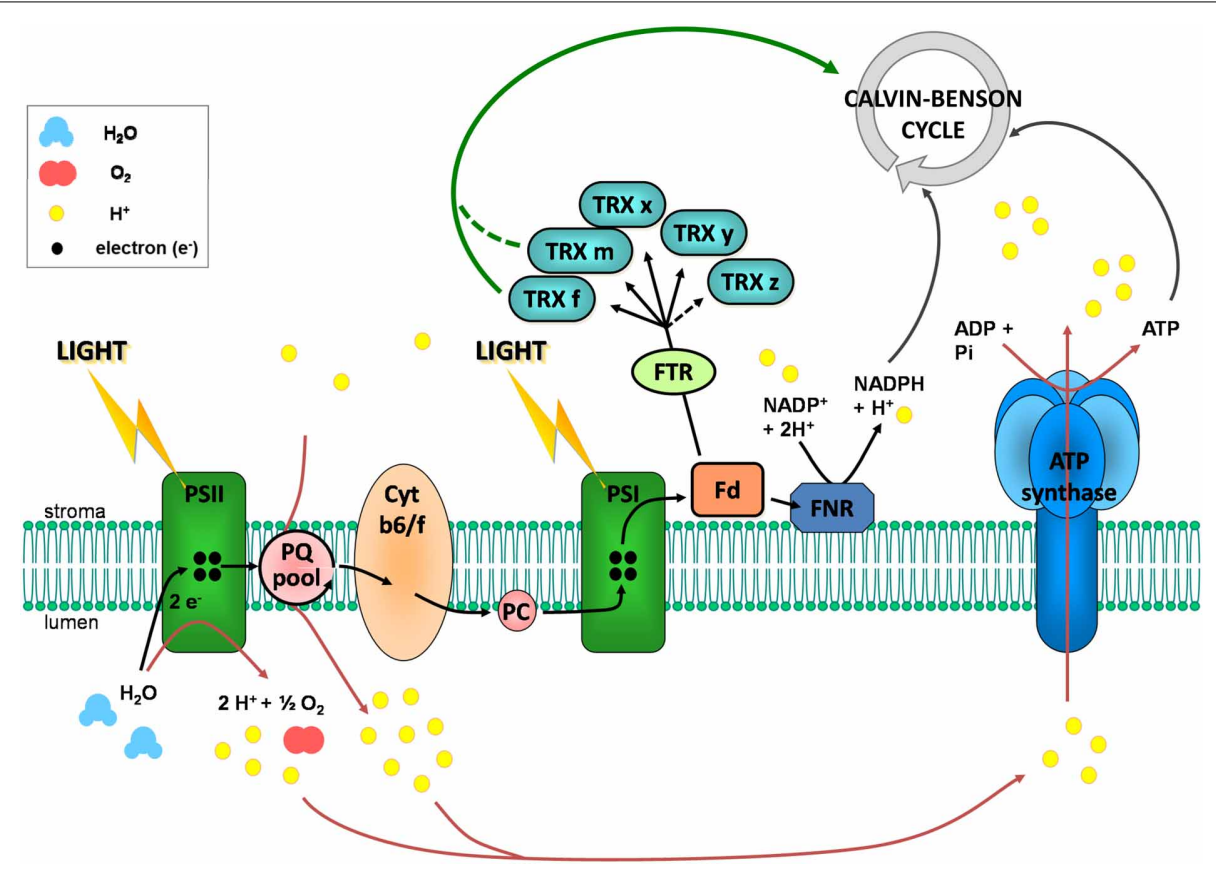

FIGURE 2 | The photosynthetic electron transfer chain and the reduction of chloroplastic TRXs. In the thylakoid membrane, when photosystem II (PSII) is excited by absorption of a photon light energy, the reaction center chlorophyll molecule transiently loses an electron. This electron is transmitted to the plastoquinone pool (PQ) which takes a proton from the stroma. Upon oxidation, the reaction center chlorophyll is a very strong oxidizing agent which is able to accept electrons from water, resulting in oxygen and protons production in the lumen. The chlorophyll can then be excited again. Reduced plastoquinone can move through the membrane from PSII to cytochrome b6/f (Cyt b6/f). There, plastoquinone is oxidized and its proton is released in the lumen, leading to a proton transport from stroma to lumen. Its electron is further transferred to photosystem I (PSI) via cytochrome b6/f and plastocyanin (PC). This electron transfer allows reduction of excited PSI reaction center chlorophyll. Upon excitation, this chlorophyll gives its electron to stromal ferredoxin ( $F d$ ) which can reduce chloroplastic thioredoxins (TRX) via the ferredoxin-thioredoxin reductase (FTR) and $\mathrm{NADP}^{+}$via the ferredoxin NADP reductase (FNR). Water photolysis and proton transport via plastoquinones contribute to the establishment of a proton gradient between stroma and lumen. This gradient is used as an energy source by the ATP synthase for ATP synthesis.

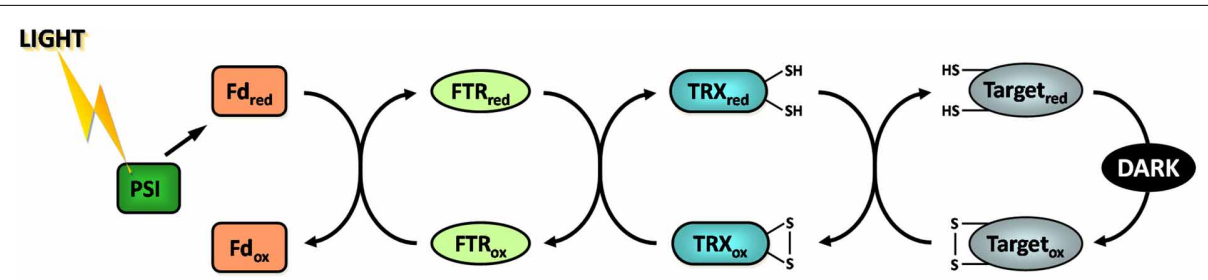

FIGURE 3 | The ferredoxin/thioredoxin system. Fd, ferredoxin; FTR, ferredoxin thioredoxin reductase; PSI, photosystem I; ox, oxidized; red, reduced.

diverse chloroplastic enzymes involved in other metabolic pathways such as ATP synthase which produces ATP in the light, Acetyl-CoA carboxylase which catalyzes the first committed step of fatty acid biosynthesis, ADP-glucose pyrophosphorylase, glucan:water dikinase and beta-amylase BAM1 involved in starch metabolism (Ballicora et al., 2000; Geigenberger et al., 2005; Mikkelsen et al., 2005; Sparla et al., 2006) or the oxidative pentose phosphate pathway enzyme glucose-6-phosphate dehydrogenase (Wenderoth et al., 1997; Nee et al., 2009). In addition to their role in the control of metabolic enzymes through reduction of regulatory disulfides, TRXs also play a major role in the detoxification of reactive oxygen species (ROS) and the maintenance of redox homeostasis in the chloroplast. Indeed, TRXs serve as substrate and provide electrons for the regeneration of different types of antioxidant chloroplast enzymes including peroxiredoxins (PRXs) (Dietz, 2011), glutathione peroxidases (GPXs) (Navrot et al., 2006) and methionine sulfoxide reductases (Tarrago et al., 2009). Early studies on the regulation of FBPase and NADP-MDH led to the identification of two types of TRX named TRXf and TRXm due to their substrate specificity (Jacquot et al., 1978; Wolosiuk et al., 1979). Indeed, TRXf was initially found to activate FBPase while TRXm appeared to preferentially activate NADP-MDH. TRXf was also found to be more effective than TRXm for the reduction of all other CBC enzymes (Wolosiuk et al., 1979).

The availability of genome sequences revealed the existence of three other types of TRXs in the chloroplast. TRXx was identified in Arabidopsis (Mestres-Ortega and Meyer, 1999), TRXy 
in Chlamydomonas (Lemaire et al., 2003), and TRXz in tomato and Arabidopsis (Rivas et al., 2004; Arsova et al., 2010; Meng et al., 2010; Schroter et al., 2010). In cyanobacteria, such as Synechocystis sp. PCC6803, four TRXs are present: 1 TRXm, 1 TRXx, 1 TRXy, and 1 TRX encoded by the $\operatorname{tr} x C$ gene that has no ortholog in eukaryotes (Chibani et al., 2009; Pérez-Pérez et al., 2009). All five chloroplast TRX types ( $\mathrm{f}, \mathrm{m}, \mathrm{x}, \mathrm{y}, \mathrm{z}$ ) are conserved in land plants which usually contain several isoforms of each TRX type, such as Arabidopsis (2 TRXf, 4 TRXm, 1 TRXx, 2 TRXy, 1 TRXz) or poplar (1 TRXf, 8 TRXm, 1 TRXx, 2 TRXy, 1 TRXz) (Lemaire et al., 2007; Chibani et al., 2009). This multiplicity is more limited in unicellular eukaryotes such as the green algae Chlamydomonas reinhardtii (2 TRXf, 1 TRXm, 1 TRXx, 1 TRXy, 1 TRXz) or Ostreococcus lucimarinus (2 TRXf, 1 TRXm, 1 TRXx, no TRXy, 1 TRXz). Although TRXx and TRXy appear to be reduced by FTR (Bohrer et al., 2012), their biochemical properties do not allow them to activate CBC enzymes. These TRX types appear to be more specifically involved in the response to oxidative stress and the maintenance of ROS homeostasis. Indeed, TRXx and TRXy were found to be the most efficient TRXs for the reduction of PRXs, GPXs and MSRs (Collin et al., 2003, 2004; Chibani et al., 2011). TRXz has been recently characterized as a subunit of the plastid encoded RNA polymerase and plays an important role in chloroplast transcription and chloroplast development (Arsova et al., 2010; Schroter et al., 2010). In addition to this role, TRXz was suggested to be redox active although its mode of reduction remains controversial since TRXz was reported to be reduced by FTR in poplar (Chibani et al., 2011) or by other TRX types in Arabidopsis (Bohrer et al., 2012). Nonetheless, as TRXx and TRXy, TRXz appears to reduce some antioxidant enzymes but is most probably not able to reduce classical carbon metabolism targets including CBC enzymes, as demonstrated for NADP-MDH (Chibani et al., 2011; Bohrer et al., 2012). By contrast, TRXf and TRXm are clearly dedicated to the regulation of the CBC although TRXf appears to play a more prominent role. Indeed, all TRX-dependent enzymes of the $\mathrm{CBC}$ analyzed are exclusively or preferentially reduced by f-type TRXs. TRXm may thus play a more important role in the regulation of other chloroplastic processes and pathways such as transfer of reducing equivalents from the stroma to the thylakoid lumen (Motohashi and Hisabori, 2006, 2010) or regulation of chloroplastic proteins involved in electron transfer pathways (Courteille et al., 2013). Alternatively, TRXm isoforms may serve as alternative regulators of some CBC enzymes when TRXf activity is limiting, e.g., under oxidative stress conditions leading to protein glutathionylation in chloroplasts. Indeed, TRXf itself can be glutathionylated and consequently lose capability to regulate its targets (Michelet et al., 2005). In addition to canonical chloroplastic TRXs, numerous non chloroplastic TRX types and TRX-like isoforms are present in the genomes of photosynthetic eukaryotes (Chibani et al., 2009). Forty-one isoforms of TRXs and TRX-like proteins were reported in Arabidopsis and forty-five in poplar. Some of these TRX-related proteins are likely located in chloroplasts as shown for the peculiar CDSP32 protein composed of two TRX domains (Broin et al., 2002) and which participates in responses to oxidative stress (Rey et al., 2005; Tarrago et al., 2010).

\section{MOLECULAR MECHANISMS OF LIGHT-DEPENDENT REGULATION OF THE CALVIN-BENSON CYCLE}

After the discovery of the Fd/TRX system, numerous efforts have been put on the analysis at the biochemical and structural level of the molecular mechanism underlying TRX-dependent activation of chloroplast enzymes. The insights obtained from these studies are detailed in this section.

\section{CALVIN-BENSON CYCLE ENZYMES Glyceraldehyde-3-phosphate dehydrogenase (GAPDH)}

GAPDH catalyzes the reversible interconversion of 1,3bisphosphoglycerate (BPGA) into glyceraldehyde-3-phosphate (G3P) (Figure 1). At difference with $\mathrm{NAD}(\mathrm{H})$-specific glycolytic GAPDH (GAPC) (Zaffagnini et al., 2013a,b, this series), photosynthetic GAPDH uses both $\operatorname{NAD}(\mathrm{H})$ and $\mathrm{NADP}(\mathrm{H})$ as coenzymes (Melandri et al., 1968). GAPDH was the first CBC enzyme reported to be activated by light: in leaves and chloroplast extracts subjected to short periods of illumination, the $\operatorname{NADP}(\mathrm{H})$-dependent activity of GAPDH was found several-fold higher than in samples maintained in the dark, but the $\operatorname{NAD}(\mathrm{H})$ GAPDH activity remained low and stable (Ziegler and Ziegler, 1965). GAPDH activation in vivo was strictly dependent on photosynthetic electron transport, i.e., was inhibited by the PSII inhibitor DCMU (3-(3,4-dichlorophenyl)-1,1-dimethylurea), and could be mimicked in vitro by addition of NADPH and the strong chemical reductant dithiothreitol (DTT) (Ziegler and Ziegler, 1966). These results were confirmed in several species of land plants and green algae (Anderson and Lim, 1972; Huber, 1978; Austin et al., 1992; Scagliarini et al., 1993; Baalmann et al., 1994). Wolosiuk and Buchanan (1978a) first demonstrated the increase of the $\mathrm{NADP}(\mathrm{H})$-dependent GAPDH activity by reduced TRX, but the complex mechanism of GAPDH regulation involves also the inter-conversion between active tetramers and low activity oligomers (Pupillo and Piccari, 1973) and this change of quaternary structure is controlled by different ligands, including $\mathrm{NAD}(\mathrm{P})(\mathrm{H})$, ATP and BPGA (Pupillo and Piccari, 1973; O’brien et al., 1976; Wolosiuk and Buchanan, 1976; Cerff, 1978; Trost et al., 1993). In vivo, oligomers can be formed by GAPDH only (Pupillo and Piccari, 1973; Scheibe et al., 2002; Howard et al., 2011b), or include PRK as suggested by early works (Wara-Aswapati et al., 1980; Nicholson et al., 1987; Avilan et al., 1997). Later, it was understood that GAPDH-PRK complexes were actually assembled by a small TRX-regulated protein named CP12 (Wedel et al., 1997; see below).

Photosynthetic GAPDH is coded by two types of genes ( $g a p A$, $g a p B$ ) in Streptophytes [land plants and Charophytes (Petersen et al., 2006)], and Prasinophycean green algae [e.g., Ostreococcus, (Robbens et al., 2007)]. The $\operatorname{gap} B$ gene is absent in all other oxygenic phototrophs that usually contain a single gapA gene, except for cryptomonads, diatoms, and chromalveolates in general in which chloroplast GAPDH is encoded by gapC-type genes (Liaud et al., 1997). At the protein level, GAPA and GAPB are almost identical, but GAPB contains a specific C-terminal extension (CTE) of about 30 amino acids (Baalmann et al., 1996). The CTE contains the pair of Cys residues that are targeted by TRX and are responsible for the light/dark regulation of the enzyme (Sparla et al., 2002) (Figure 4). GAPA, or A-subunits, form stable 


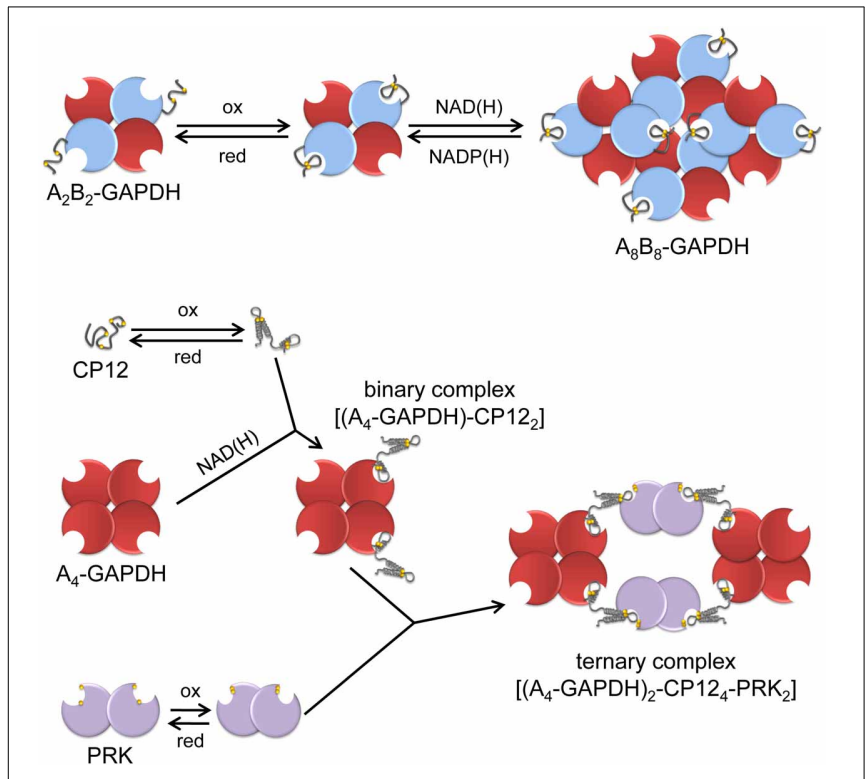

FIGURE 4 | A schematic view of the regulation and interactions of chloroplast $\mathbf{A}_{\mathbf{4}}$-GAPDH, CP12, PRK and AB-GAPDH. "Light conditions" (left side of the figure), consisting of increased levels of reduced TRXs and high $\mathrm{NADP}(\mathrm{H}) / \mathrm{NAD}(\mathrm{H})$ ratio, promote the reduction and dissociation of the supramolecular complexes. $\mathrm{A}_{4}-\mathrm{GAPDH}$, reduced $\mathrm{PRK}$ and reduced $A_{2} B_{2}-G A P D H$ are fully active in the light while reduced CP12 does not interact with partner proteins. "Dark conditions"(right side of the figure), consisting of decreased level of reduced TRXs and low NADP(H)/NAD $(H)$ ratio, promote disulfide formation in PRK, CP12 and $A_{2} B_{2}-G A P D H$. These conditions promote the formation of the binary complex between $\mathrm{A}_{4}-\mathrm{GAPDH}$ and oxidized $\mathrm{CP} 12$ that further reacts with oxidized PRK forming the ternary complex $A_{4}$-GAPDH/CP12/PRK. Concomitantly, $A_{2} B_{2}-G A P D H$ undergoes oxidation and shifts to oligomeric form $\left(A_{8} B_{8}-G A P D H\right)$. Within these complexes, the activity of both GAPDHs and PRK is strongly suppressed.

homotetramers [A - GAPDH, (Fermani et al., 2001)] that resemble the structure of glycolytic GAPDHs (Zaffagnini et al., 2013a,b, this series), or alternatively bind B-subunits in stoichiometric ratio to form heterotetramers $\left(\mathrm{A}_{2} \mathrm{~B}_{2}\right)$ and higher order oligomers [mainly $\mathrm{A}_{8} \mathrm{~B}_{8}$; (Pupillo and Piccari, 1973)]. $\mathrm{A}_{4}-\mathrm{GAPDH}$ is a minor GAPDH isoform in higher plants (Scagliarini et al., 1993; Howard et al., 2011b), but is the only isoform of photosynthetic GAPDH in green algae, red algae and cyanobacteria (Petersen et al., 2006). Lacking the CTE, $\mathrm{A}_{4}-\mathrm{GAPDH}$ is not TRX-regulated per se but acquires this regulation through the interaction with the TRX-regulated proteins CP12 and PRK (Wedel and Soll, 1998; Graciet et al., 2004; Trost et al., 2006). This is the only known mechanism of light/dark regulation of GAPDH in green algae and cyanobacteria, and it will be discussed further below in the section on CP12. In chloroplasts of $\mathrm{C}_{3}$ plants, CTE- and CP12-based regulation of GAPDH co-exist (Scheibe et al., 2002), and CP12assembled complexes may contain either $\mathrm{A}_{4}-$ or $\mathrm{A}_{2} \mathrm{~B}_{2}-\mathrm{GAPDH}$ (Carmo-Silva et al., 2011; Howard et al., 2011b). In $\mathrm{C}_{4}$ plants, the two systems appear instead to be separated: a proteomic study on maize revealed that $\mathrm{CP} 12$ is enriched in bundle sheath chloroplasts, together with GAPA and PRK, while GAPB is enriched in mesophyll chloroplasts (Majeran et al., 2005).
In land plants, the activity of AB-GAPDH isoforms primarily depends on the redox state of the two cysteines of the CTE [Cys349 and Cys358 in spinach (Sparla et al., 2002)]. The Cys349Cys358 disulfide has a midpoint redox potential of $-353 \mathrm{mV}$ at $\mathrm{pH} 7.9$ and is specifically reduced by TRXf (Marri et al., 2009). In the presence of reduced TRXf and at NADPH concentrations expected for illuminated chloroplasts, the NADPHactivity of AB-GAPDH is maximal and the enzyme is tetrameric (Scagliarini et al., 1993; Baalmann et al., 1994; Sparla et al., 2002). In this activated form, the $2^{\prime}$-phosphate group of NADPH interacts with Arg77 and Ser188, and these interactions are crucial for both coenzyme specificity [NADH contains an $-\mathrm{OH}$ in the 2'-position; (Falini et al., 2003)] and TRX-dependent regulation of GAPDH (Fermani et al., 2007). In fact, the disulfide bond between Cys349 and Cys358 shapes the CTE into a bulky hairpin structure that is harbored in proximity of the coenzyme-binding site. In this position, the negatively charged CTE distracts Arg77 from the 2 -phosphate of bound NADPH, with the consequence of depressing the NADPH-dependent activity, while leaving unaffected the $\mathrm{NADH}$-dependent one. Both the crystal structure of oxidized $\mathrm{A}_{2} \mathrm{~B}_{2}-\mathrm{GAPDH}$ (Fermani et al., 2007) and the kinetic characterization of site-specific mutants (Sparla et al., 2005) support this regulatory mechanism in which the CTE of GAPB acts as a redox-sensitive auto-inhibitory domain.

The CTE also controls the capability of $\mathrm{A}_{2} \mathrm{~B}_{2}-\mathrm{GAPDH}$ to associate into the $\mathrm{A}_{8} \mathrm{~B}_{8}$ isoform upon binding $\mathrm{NAD}(\mathrm{H})$ in place of $\operatorname{NADP}(\mathrm{H})$ (Figure 4). The effect is completely dependent on the CTE that must bear the Cys349-Cys358 disulfide (Baalmann et al., 1996; Sparla et al., 2002). Oligomeric AB-GAPDH has very low NADPH-activity and accumulates in chloroplasts in the dark (Scagliarini et al., 1993; Baalmann et al., 1994). Full recovery of GAPDH activity is obtained by reducing the CTE with reduced TRXf or by displacing oxidized CTE from the active site with ligands such as $\operatorname{NADP}(\mathrm{H})$, ATP, or BPGA (Trost et al., 2006). As recalled below, the CTE is homologous to the C-terminal half of $\mathrm{CP} 12$ and CP12 is engaged in protein-protein interactions with GAPA and PRK when containing a disulfide bond.

\section{Phosphoribulokinase (PRK)}

PRK catalyzes the phosphorylation of ribulose-5-phosphate to ribulose-1,5-bisphophate using ATP generated by thylakoid ATP synthase (Figure 1). The light-dependent activation of PRK was initially reported in the unicellular green alga Chlorella (Pedersen et al., 1966; Bassham, 1971) and later confirmed with isolated chloroplasts from spinach (Latzko et al., 1970; Avron and Gibbs, 1974). As in the case of GAPDH, the activation of PRK was found to be blocked by DCMU (Latzko et al., 1970; Avron and Gibbs, 1974; Champigny and Bismuth, 1976) and mimicked by DTT (Latzko et al., 1970; Anderson, 1973b; Anderson and Avron, 1976). Contrary to GAPDH, PRK has no cytosolic counterpart since this enzyme exclusively participates in the CBC. The enzyme is a homodimer in eukaryotes (Porter et al., 1986) and a homotetramer in cyanobacteria (Wadano et al., 1998). In anoxygenic photosynthetic prokaryotes PRK is octameric, but is not redox-regulated (Harrison et al., 1998). In plants, each PRK monomer contains 4 strictly conserved cysteines. PRK 
has a low activity in the oxidized form and is activated by TRX (Wolosiuk and Buchanan, 1978b). The molecular mechanism of PRK redox regulation was investigated on the spinach enzyme by chemical modification and site-directed mutagenesis of Cys16 and Cys55 that are located on the N-terminal part of the monomer and form a disulfide reduced by TRX (Porter and Hartman, 1988; Milanez et al., 1991; Brandes et al., 1996). Since Cys55 appears to play an important role in the catalysis by binding the sugar phosphate substrate (Porter and Hartman, 1990; Milanez et al., 1991), formation of the Cys16-Cys55 disulfide efficiently blocks the activity. The midpoint redox potential of PRK was found somehow variable between species [at $\mathrm{pH}$ 7.9: $-315 \mathrm{mV}$ in tomato (Hutchison et al., 2000); $-330 \mathrm{mV}$ in Arabidopsis (Marri et al., 2005); $-349 \mathrm{mV}$ in spinach (Hirasawa et al., 1999)], but tends to be less negative compared to that measured for other CBC enzymes [between -350 and $-385 \mathrm{mV}$ (Hirasawa et al., 1999, 2000; Hutchison et al., 2000; Sparla et al., 2002; Marri et al., 2005)]. Recently, the TRX specificity for Arabidopsis PRK activation was investigated and TRXf was found to be the most efficient compared to m-type TRXs, while no PRK reactivation was observed with $\mathrm{x}$ - and y-types TRXs (Marri et al., 2009). The three dimensional structure of plant PRK remains unknown precluding full understanding of the molecular mechanisms involved in the redox regulation mediated by TRX.

\section{Fructose-1,6-bisphosphatase (FBPase)}

FBPase catalyzes the dephosphorylation of fructose-1,6bisphosphate (FBP) into fructose-6-phosphate (F6P) with the concomitant release of inorganic phosphate (Figure 1). The enzyme is a homotetramer of $c a .160 \mathrm{kDa}$. The cytosolic isoform of FBPase, which participates in gluconeogenesis, is not redox regulated by TRX. The light-dependent activation of FBPase was also initially reported in Chlorella (Pedersen et al., 1966; Bassham, 1971) and later confirmed in isolated chloroplasts from higher plants where the activation was found to be DCMU sensitive (Champigny and Bismuth, 1976; Kelly et al., 1976) and could be mimicked by DTT (Baier and Latzko, 1975). Oxidized FBPase has a basal activity (20-30\%) and becomes fully activated upon disulfide reduction which is strictly dependent on TRXf, all other TRX types being inefficient. The molecular mechanism of TRX dependent activation of FBPase was initially unraveled for pea FBPase. Compared to its cytosolic counterparts, pea stromal FBPase contains two insertions of 5 and 12 amino acids containing 1 (Cys153) and 2 cysteines (Cys173 and Cys178), respectively. The mutation C153S or the double mutation C173S/C178S yielded a permanently active FBPase while the single mutant $\mathrm{C} 173 \mathrm{~S}$ and $\mathrm{C} 178 \mathrm{~S}$ retained a partial redox dependent regulation (Jacquot et al., 1995, 1997). These results suggested that the regulatory disulfide is formed between Cys153 and either with Cys173 or Cys178. The structure of pea FBPase revealed the presence of a unique Cys153-Cys173 disulfide, suggesting that the Cys153-Cys178 disulfide was only formed upon mutation of Cys173 although a more complex regulation implicating isomerization of disulfide bonds could not be completely ruled out (Chiadmi et al., 1999). Strikingly similar results were obtained for the 3 cysteines present in the insertions found in rapeseed FBPase (Rodriguez-Suarez et al., 1997). The midpoint redox potential of the regulatory disulfide bond was found to be $-369 \mathrm{mV}$ and $-384 \mathrm{mV}$ at $\mathrm{pH} 7.9$ for pea and spinach FBPases, respectively (Hirasawa et al., 1999). Comparison of the structure of oxidized and reduced FBPase allowed understanding the conformational changes linking the redox state of the regulatory disulfide and the level of activation of the enzyme (Villeret et al., 1995; Chiadmi et al., 1999; Dai et al., 2004). Although the regulatory disulfide is at a distance of more than $20 \AA$ from the active site, its formation forces a loop connecting two antiparallel beta strands to slide in toward the active site, thereby disrupting the binding sites for the catalytic $\mathrm{Mg}^{2+}$ cations (Chiadmi et al., 1999). Therefore, in light-regulated FBPase, the regulatory insertions that form the disulfide do not interact directly with the active site (like in malate dehydrogenase as described below) or in its proximity (like in AB-GAPDH), but stabilizes a general conformation in which the active site is almost non-functional.

\section{Sedoheptulose-1,7-bisphosphatase (SBPase).}

SBPase catalyzes the dephosphorylation of sedoheptulose-1,7bisphosphate (SBP) into sedoheptulose-7-phosphate (S7P) with the concomitant release of inorganic phosphate (Figure 1). SBPase is a homodimer of $c a .70 \mathrm{kDa}$ that is unique to the $\mathrm{CBC}$ and has no cytosolic counterpart. SBPase is found in all photosynthetic eukaryotes but not in cyanobacteria which encode a bifunctional FBPase possessing also SBPase activity (Tamoi et al., 1996). As in the case of GAPDH and FBPase, the lightdependent activation of SBPase was also initially reported in Chlorella (Pedersen et al., 1966; Bassham, 1971), confirmed in isolated chloroplasts from land plants and found to be mimicked by DTT (Anderson, 1974; Schürmann and Buchanan, 1975; Anderson and Avron, 1976). By contrast with other CBC enzymes, the oxidized form of SBPase is completely inactive and its reactivation absolutely requires the TRX-mediated light activation. SBPase redox regulation has only been analyzed for the wheat enzyme that possesses 7 cysteines among which 4 are strictly conserved in all organisms. Site-directed mutagenesis of the wheat enzyme suggested the existence of a single regulatory disulfide between Cys52 and Cys57 (Dunford et al., 1998). However, in this study, the activity of recombinant wheat mutant SBPase was only measured in E. coli crude extracts using DTT as electron donor that may have mediated SBPase activation through E. coli TRXs. Therefore, the molecular mechanism underlying the redox regulation of SBPase remains to be clearly established with the purified enzyme. The enzyme from maize leaves was reported to be, like FBPase, specifically activated by TRXf (Nishizawa and Buchanan, 1981) but not all TRX types have yet been tested. SBPase sequences share a significant homology with FBPase, possibly due to a common origin (Raines et al., 1992; Martin et al., 1996). Therefore, although the structure of plant SBPase remains undetermined, a model has been proposed based on the structure of pig FBPase (Dunford et al., 1998). This model suggested that like in FBPase, the reduction of SBPase disulfide would trigger its activation through a general conformational change of the enzyme that shapes the active site. 


\section{OTHER TRX-DEPENDENT ENZYMES LINKED TO THE CALVIN-BENSON CYCLE \\ NADP-dependent malate dehydrogenase (NADP-MDH)}

NADP-MDH catalyzes the reduction of oxaloacetate (OAA) into malate using NADPH as electron donor. The enzyme is a homodimer of $c a$. $70 \mathrm{kDa}$. NADP-MDH plays a key role for $\mathrm{CO}_{2}$ fixation in $\mathrm{C} 4$ and CAM plants where photorespiration, linked to the oxygenase activity of Rubisco, is limited through an alternative $\mathrm{CO}_{2}$ fixation pathway initiated by phosphoenolpyruvate carboxylase (PEPC) (Foyer et al., 2009) (Figure 5). $\mathrm{CO}_{2}$ fixation by PEPC yields oxaloacetate that is converted to malate by NADP-MDH. The malic enzyme converts malate into phosphoenolpyruvate and $\mathrm{CO}_{2}$ in the proximity of Rubisco. These carbon concentration mechanisms limit photorespiration and ensure optimal photosynthesis efficiency under specific growth conditions. In C3 plants, NADP-MDH is involved in the export of reducing power, in the form of malate, from the stroma to the cytosol through the malate valve. Light-dependent activation of NADP-MDH was initially reported in C4 plants (Johnson and Hatch, 1970) and later confirmed in C3 plants (Johnson, 1971). As in the case of CBC enzymes, the light-dependent activation was confirmed on isolated chloroplasts, found to be blocked by DCMU and mimicked by DTT (Anderson, 1973a; Anderson and Avron, 1976). NADP$\mathrm{MDH}$ is probably one of the best studied light-regulated enzyme in the chloroplast both at the molecular and structural levels. By contrast with most $\mathrm{CBC}$ enzymes which exhibit a basal activity in the oxidized form, oxidized NADP-MDH is totally inactive and strictly dependent on light-driven TRX activation. The molecular mechanism of NADP-MDH activation has been initially unraveled on the enzyme from the C4 plant Sorghum bicolor. Compared to the redox independent NAD-dependent $\mathrm{MDH}$ isoforms, Sorghum NADP-MDH possesses N- and C-terminal extensions and contains 8 cysteine residues strictly conserved in land plants. Site-directed mutagenesis and chemical modifications allowed understanding the molecular mechanism of TRX-dependent activation of this enzyme (reviewed in MiginiacMaslow and Lancelin, 2002). Two regulatory disulfides, located in each extension, are present in the oxidized form and have to be both reduced by TRX for full activation of the enzyme. Reduction of the Cys24-Cys29 N-terminal disulfide allows a slow conformational change of the enzyme while reduction of the Cys365-Cys377 C-terminal disulfide is required to give access to the active site (Issakidis et al., 1992, 1993, 1994, 1996; Lemaire et al., 1994). Indeed, in the oxidized form, the penultimate glutamate residue interacts with the active site Arg204 thereby blocking access of OAA (Ruelland et al., 1997; Hirasawa et al., 2000). In addition, the internal Cys207 can form a TRX-reducible disulfide with Cys24, suggesting that disulfide isomerization may be required during activation (Ruelland et al., 1997; Hirasawa et al., 2000). These results were later found to be consistent with the structures of Sorghum and Flaveria NADP-MDH (Carr et al., 1999; Johansson et al., 1999) and have allowed to propose a detailed model of the molecular mechanism of activation of NADP-MDH (Figure 6). The standard redox potentials of the two regulatory disulfides are not equivalent, the $\mathrm{N}$-terminal disulfide $\left(E_{m}=-344 \mathrm{mV}\right.$ at $\left.\mathrm{pH} 7.9\right)$ being more positive, and therefore easier to reduce, than the C-terminal disulfide $\left(E_{m}=-384 \mathrm{mV}\right.$
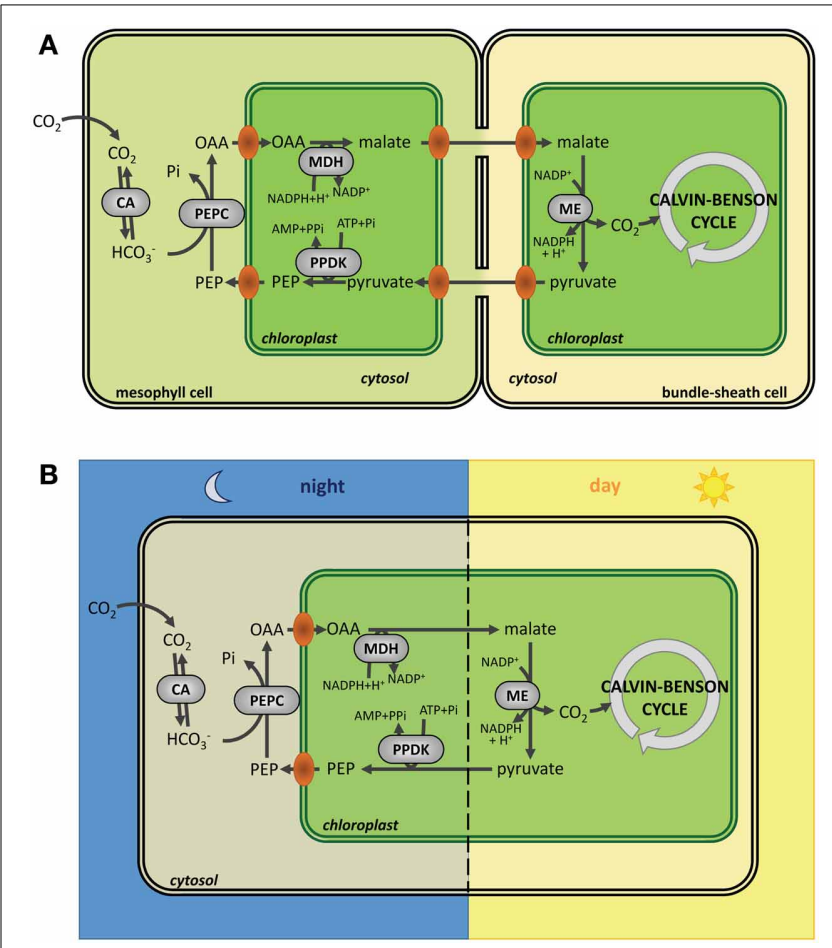

FIGURE 5 | Carbon fixation in C4 and CAM plants. (A) Carbon fixation in C4 plants. Compared to C3 plants, carbon fixation in C4 plants occurs in two steps: $\mathrm{CO}_{2}$ is first fixed by PEPC (phosphoenolpyruvate carboxylase) in mesophyll cells to form oxaloacetate (OAA) that is converted to malate by NADP-MDH (NADP-malate dehydrogenase) before export to bundle sheath cells were $\mathrm{CO}_{2}$ is released by $\mathrm{ME}$ (malic enzyme). Finally, $\mathrm{CO}_{2}$ is fixed by Rubisco. (B) Carbon fixation in CAM plants. In CAM plants, carbon fixation is split in two steps, but, compared to $\mathrm{C} 4$ plants, this fixation is separated in time instead of being separated in space with cells fixing $\mathrm{CO}_{2}$ by PEPC (phosphoenolpyruvate carboxylase) and accumulating malate during the night before release of $\mathrm{CO}_{2}$ by $\mathrm{ME}$ (malic enzyme) and fixation by Rubisco during the day. $\mathrm{CA}$, carbonic anhydrase; $\mathrm{PEPC}$, phosphoenolpyruvate carboxylase; MDH, NADP malate dehydrogenase; ME, malic enzyme; PPDK, pyruvate, phosphate dikinase; OAA, oxaloacetate; PEP, phosphoenolpyruvate.

at $\mathrm{pH}$ 7.9) that will require an excess of reduced TRX for its reduction. This difference suggests the existence of a sequential activation: reduction of the N-terminal disulfide would occur first and allow "pre-reduction" of the enzyme in a form that can be rapidly activated when the reducing power of the chloroplast reaches a threshold level. The knowledge acquired on the redox regulation of Sorghum NADP-MDH allowed transforming the constitutively active NAD-MDH from the thermophilic bacteria Thermus flavus into a TRX-dependent enzyme by grafting of the Sorghum N- and C-terminal extensions (Issakidis-Bourguet et al., 2006).

Interestingly, Chlamydomonas NADP-MDH was found to also possess $\mathrm{N}$ - and $\mathrm{C}$-terminal extensions but the $\mathrm{N}$-terminal extension does not contain any cysteine. The enzyme is also strictly dependent on TRX-mediated activation through reduction of a single regulatory disulfide located in its C-terminal extension (Lemaire et al., 2005). The redox potential of this disulfide $\left(E_{m}=-369 \mathrm{mV}\right.$ at $\left.\mathrm{pH} 7.9\right)$ is more positive than the 


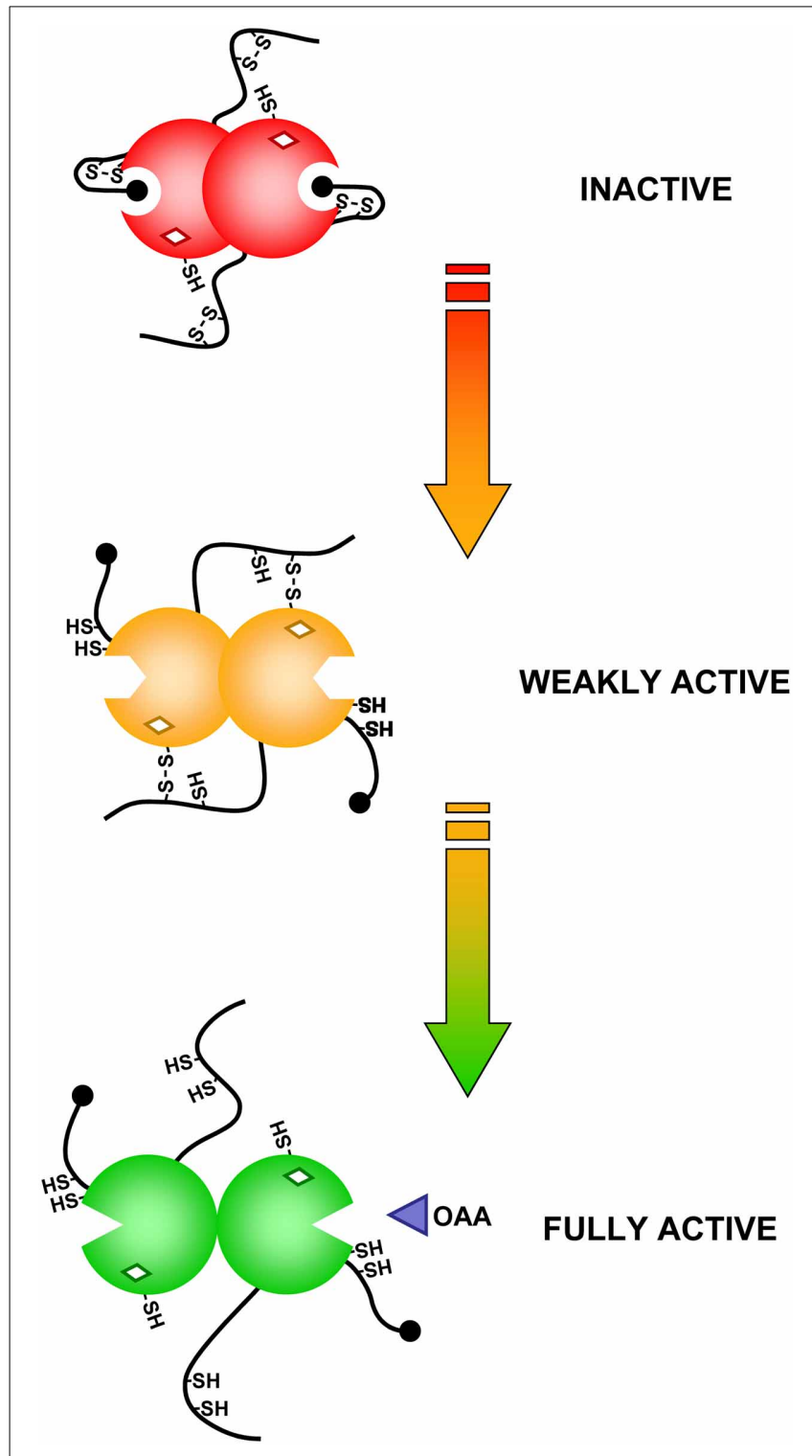

FIGURE 6 | Schematic representation of the activation mechanism of Sorghum NADP-MDH.

C-terminal disulfide of Sorghum NADP-MDH $\left(E_{m}=-384 \mathrm{mV}\right.$ $\mathrm{pH}$ 7) and can be reduced by both TRXm and TRXf1 from Chlamydomonas. Conversely, Chlamydomonas TRXf1 is not able to activate Sorghum NADP-MDH, suggesting structural and thermodynamic differences between algal and land plants TRXf. Analysis of different Sorghum NADP-MDH mutants suggested that the redox potential of the algal TRXf is significantly lower than that of land plant TRXf (Lemaire et al., 2005). This surprising result suggests the existence of a coevolution of the redox properties of TRXs and NADP-MDH. From an evolutionary point of view, the redox regulation of Chlamydomonas NADP-MDH appears like a first step toward the complex regulation existing in land plants. The requirement for such a sophisticated control may be linked to the multicellular nature of land plants where malate is a circulating form of reducing power (Scheibe, 2004) while in Chlamydomonas malate is only exchanged between the unique chloroplast and the cytosol. These results also suggest that the redox regulatory sequences have been progressively added to non-regulated enzymes during the course of evolution.

\section{Rubisco activase}

Rubisco activase is a molecular chaperone of the AAA+ family that uses the energy from ATP hydrolysis to release tight binding inhibitors from the active site of Rubisco (reviewed in Portis, 2003; Portis et al., 2008). The ATPase activity of Rubisco activase is controlled by the ADP/ATP ratio and/or by the Fd/TRX system. In many species, such as Arabidopsis, two isoforms of activase are present: a short form (beta isoform) and a long form (alpha isoform). The two forms are either generated by alternative splicing or encoded by distinct genes (Werneke and Ogren, 1989; Salvucci et al., 2003; Yin et al., 2010). Compared to the beta isoform, the alpha isoform differs by the presence of a C-terminal extension containing two conserved cysteines. In Arabidopsis, site-directed mutagenesis revealed that these residues, Cys392 and Cys411, form a disulfide reduced by TRXf in the light (Zhang et al., 2001). The extension contains negative charges that interact with the ATP binding site (Wang and Portis, 2006; Portis et al., 2008). Indeed, the oxidized enzyme has a decreased affinity for ATP and is inhibited by ADP while reduction by TRXf alleviates this inhibition. This regulation controls the activity of both alpha and beta isoforms in the holoenzyme (Zhang et al., 2001). Some species such as tobacco, maize, or green algae only contain the short beta isoform but still exhibit light dependent regulation of Rubisco activase activity (Salvucci et al., 1987). A recent study revealed that tobacco beta isoform, by contrast with the beta isoform from Arabidopsis, has a unique sensitivity to $\mathrm{ADP} / \mathrm{ATP}$ ratios that is responsible for the light regulation of the activity (Carmo-Silva and Salvucci, 2013). Several studies have concluded that Rubisco activase forms hexamers in solution, and that this may be the active form (Keown et al., 2013; Mueller-Cajar et al., 2013). The structure of tobacco Rubisco activase forms a helical arrangement in the crystal structure, with six subunits per turn (Stotz et al., 2011). However, Rubisco activase appears to form a wide range of structures in solution, ranging from monomers to oligomers, and an open spiraling structure rather than a closed hexameric structure has been recently proposed (Keown et al., 2013). Numerous features of Rubisco activase are reminiscent of GAPDH which also can assemble into higher oligomeric states and has both redox-regulated (GAPB) and non-redox-regulated (GAPA) subunits that differ by a Cterminal extension containing a TRX-reduced regulatory disulfide that exerts control on the activity of the mixed oligomer $\left(A_{n} B_{n}-G A P D H\right)$.

\section{CP12}

CP12 was discovered by serendipity in higher plants as a novel protein of 78 amino acids with a C-terminal sequence homologous to the CTE of GAPB subunits of GAPDH (Pohlmeyer et al., 1996). CP12 was then found to be widespread in oxygenic photosynthetic organisms, including cyanobacteria, and GAPB 
subunits of land plants are now believed to be the result of a gene fusion event between GAPA and CP12 that must have occurred at the origins of Streptophytes (Petersen et al., 2006) or before (Robbens et al., 2007).

Most CP12s contain four conserved cysteines able to form two disulfide bonds (Groben et al., 2010; Marri et al., 2010; Stanley et al., 2013). CP12 from both Synechococcus sp. PCC7942, Chlamydomonas and Arabidopsis were the most extensively studied. The protein is intrinsically disordered, particularly so when it is fully reduced, but still poorly structured when it bears both disulfide bonds (Graciet et al., 2003; Marri et al., 2008, 2010). In Arabidopsis, the C-terminal disulfide has redox properties similar to GAPB disulfide $\left[E_{m}=-352 \mathrm{mV}\right.$ at $\mathrm{pH} 7.9$, (Marri et al., 2008)] and is reduced by TRXs, though with no strict specificity (Marri et al., 2009). Oxidized CP12 binds to $\mathrm{A}_{4}-\mathrm{GAPDH}$ more tightly than CTE through interactions with both the bound coenzyme and the catalytic site of the enzyme. (Fermani et al., 2007, 2012; Matsumura et al., 2011). In Arabidopsis (Marri et al., 2008; Fermani et al., 2012) and Chlamydomonas (Kaaki et al., 2013), $\mathrm{A}_{4}$-GAPDH binds two CP12, while four CP12 are bound to $\mathrm{A}_{4}-\mathrm{GAPDH}$ in Synechococcus (Matsumura et al., 2011). CP12 binding is very strong in Chlamydomonas $\left(\mathrm{k}_{D}\right.$ $0.4 \mathrm{nM}$ ) and causes inhibition of GAPDH activity (Erales et al., 2011), whereas in Arabidopsis CP12 binding is much weaker [ $\mathrm{k}_{\mathrm{D}} 0.2 \mu \mathrm{M}$, (Marri et al., 2008)] and inhibition is negligible (Marri et al., 2005, 2008). However, in these and other organisms, the binary complex GAPDH/CP12 can then bind PRK forming the GAPDH/CP12/PRK ternary complex, in which both enzyme activities are strongly down-regulated (Marri et al., 2005). $\mathrm{NAD}(\mathrm{H})$ binding to GAPDH is an absolute requirement for complex formation because the $2^{\prime}$-phosphate of NADPH sterically hinders the attachment of CP12 (Matsumura et al., 2011; Fermani et al., 2012). Dissociation of the complex, and recovery of enzyme activity is rapidly obtained by reduced TRXs (Marri et al., 2009), but also by BPGA, NADPH or ATP that displace CP12 from its binding sites on GAPDH and PRK, respectively (Wedel et al., 1997; Scheibe et al., 2002; Graciet et al., 2004; Marri et al., 2005; Tamoi et al., 2005; Howard et al., 2008). CP12-assembled complexes of GAPDH and PRK accumulate in the dark, both in cyanobacteria and in chloroplasts, probably favored by the oxidation of the TRX pool and by low $\mathrm{NADP}(\mathrm{H}) / \mathrm{NAD}(\mathrm{H})$ ratios (Scheibe et al., 2002; Tamoi et al., 2005; Howard et al., 2008, 2011b). In Synechococcus, inactivation of $c p 12$ gene impaired cell growth in normal lightdark cycles, but not under continuous illumination, supporting the role of $\mathrm{CP} 12$ in light-dark regulation of the $\mathrm{CBC}$ in this organism (Tamoi et al., 2005). CP12 is also coded by the small genome of cyanophages that infect marine cyanobacteria including Synechococcus, apparently with the function of redirecting the carbon flux of the prokaryote from the $\mathrm{CBC}$ to the pentose phosphate pathway, thereby sustaining NADPH production for phage replication (Thompson et al., 2011). However, other functions of CP12 have been proposed, particularly in land plants like tobacco, where antisense suppression of CP12 severely restricts growth and alters carbon partitioning through mechanisms that are still poorly understood (Howard et al., 2011a).

\section{EVOLUTION OF REGULATORY SEQUENCES}

Comparison of the redox regulatory properties of enzymes from cyanobacteria, diatoms, algae and higher plants suggest that the light-dependent regulation mediated by TRX has been progressively introduced during evolution (Ruelland and MiginiacMaslow, 1999; Lemaire et al., 2007) (Figure 7). Comparison with non-redox-regulated forms suggest that regulatory sequences have been grafted within $\mathrm{N}$ - or C-terminal extensions (GAPDH, NADP-MDH, Rubisco Activase) or inserted in the sequence (FBPase). For some enzymes, there is no obvious insertion or extension but this mainly applies to enzymes unique to the CBC (PRK, SBPase). Interestingly, in the diatom O. sinensis PRK contains the regulatory cysteines but the redox potential of the disulfide is less negative than in PRK from higher plants, suggesting that the enzyme might not be regulated by TRX in vivo (Michels et al., 2005). In a survey on different algal groups, redoxregulation of PRK was found to be greatest in chlorophytes, but low or absent in a red alga and most chromalveolates (including diatoms), and linked to the number of amino acids separating the two regulatory cysteine residues (Maberly et al., 2010). Several other enzymes in diatoms may also be TRX independent due to the absence of regulatory cysteines such as NADP-MDH (Ocheretina et al., 2000) or GAPDH (Liaud et al., 2000).

\section{PROTEOMICS UNRAVEL NEW REDOX-DEPENDENT REGULATIONS}

Recent advances in the field of proteomics and genomics associated with our increasing understanding of redox posttranslational modifications have considerably challenged our current models of the redox dependent regulation of the $\mathrm{CBC}$ described in the above sections. These new data suggest that all enzymes of the $\mathrm{CBC}$ are regulated by a complex network of redox PTMs that is only starting to emerge. The following sections will describe these new developments and discuss their potential physiological and cellular importance.

\section{THIOREDOXIN TARGETS}

As described above, the availability of plant genome sequences revealed the existence of an unsuspected multiplicity of TRXs. At the beginning of the 2000s, the number of TRXs was even higher than the number of known TRX-regulated targets. This multiplicity raised questions about the specificity of the different TRX isoforms for their target enzymes. Moreover, systematic biochemical analysis of the ability of Arabidopsis TRX isoforms to activate different chloroplastic TRX targets revealed that TRXs are not equivalent and exhibit strong specificities (Collin et al., 2003 , 2004). This suggested that additional TRX targets probably remained to be identified and prompted several groups to develop new proteomic-based strategies to identify these unrecognized targets (reviewed in Lemaire et al., 2007; Schürmann and Buchanan, 2008; Lindahl et al., 2011). Two main strategies have been employed. The most common is based on the ability of a monocysteinic TRX to form covalent heterodimers with its target enzymes. Indeed, studies on the reaction mechanism allowing the reduction of an oxidized target by a reduced TRX had established that the most N-terminal cysteine of TRX active site performs an initial nucleophilic attack leading to the formation 


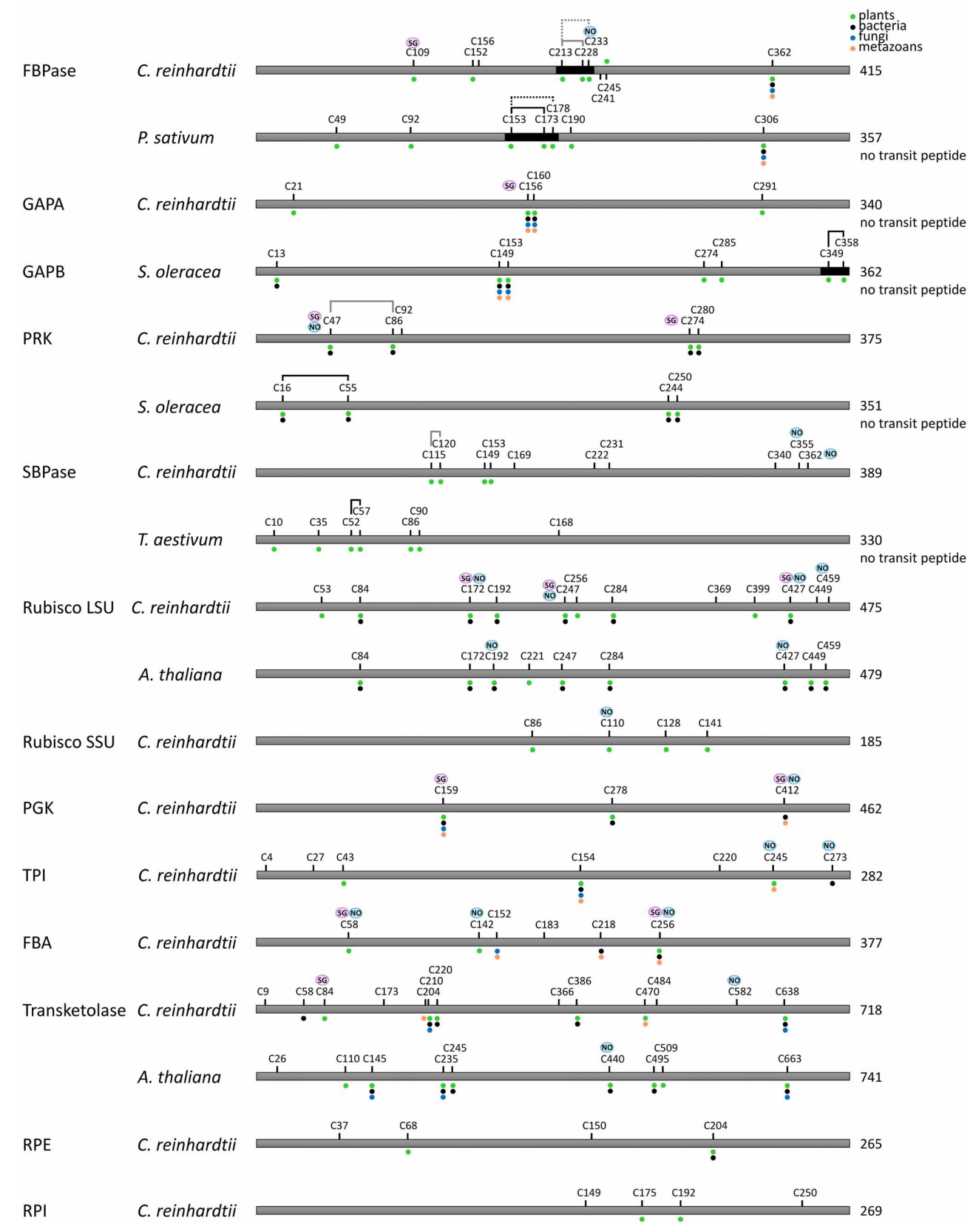

FIGURE 7 | Redox regulated cysteines in Calvin-Benson cycle enzymes. All proteins are schematically represented linearly. The numbering corresponds to the sequence with the transit peptide, except when "no transit peptide" is indicated on the right. Lines between cysteines indicate confirmed (black) or suggested (black and dashed) disulfide bonds, whereas gray lines indicate putative regulatory disulfides in $C$. reinhardtii by homology with the disulfide identified for other species. Cysteines identified as nitrosylated and glutathionylated are labeled with NO (blue) and SG (purple), respectively. The dots indicate cysteine conservation in photosynthetic organisms (green), bacteria (black), fungi (blue) and metazoans (orange). Dark boxes correspond to insertions/extension present in the TRX-regulated isoforms and absent in the isoforms not regulated by TRX. of a transient mixed-disulfide between the TRX and the target. This mixed-disulfide is then immediately reattacked by the second cysteine of the active site to yield an oxidized TRX and a reduced target. Consequently, mutating the second cysteine of the active site allows stabilization of the mixed-disulfide. TRXaffinity columns, based on a resin-bound monocysteinic TRX, have been employed to trap TRX targets which can be eluted by DTT reduction and identified by proteomic analysis. Many targets have been identified using this type of affinity columns (Motohashi et al., 2001; Goyer et al., 2002; Balmer et al., 2003, 2004b, 2006b; Lindahl and Florencio, 2003; Lemaire et al., 2004; Wong et al., 2004; Yamazaki et al., 2004; Hosoya-Matsuda et al., 
2005; Marchand et al, 2006; Marchand et al., 2010; Pérez-Pérez et al., 2006, 2009). In addition, affinity columns based on wildtype TRX have also been used to detect proteins interacting electrostatically with TRX (Balmer et al., 2004a). The second most widely used approach is based on the visualization of proteins reduced by TRX in vitro by specific labeling of exposed thiols by fluorescent probes like monobromobimane ( $\mathrm{mBBr}$ ) (Yano et al., 2001; Marx et al., 2003; Wong et al., 2003, 2004; Balmer et al., 2006a,b; Yano and Kuroda, 2006; Hall et al., 2010) or Cy5 maleimide (Maeda et al., 2004) or by radioactive probes like ${ }^{14} \mathrm{C}$ iodoacetamide (Marchand et al., 2004; Marchand et al, 2006). A comparison between both methods suggested that they are complementary since only a partial overlap is found between the different targets identified (Marchand et al, 2006).

All these proteomic studies have allowed identifying more than 300 putative TRX targets from the cyanobacteria Synechocystis sp. PCC6803, the unicellular green alga Chlamydomonas reinhardtii and numerous higher plant species (reviewed in Michelet et al., 2006; Lindahl et al., 2011). These proteomic methods are therefore powerful but they also suffer from a lack of specificity. Indeed, proteomic approaches with different types of TRX yielded roughly the same targets while a strong or exclusive specificity of most targets for a specific TRX type is generally observed in vitro. For example, columns based on monocysteinic TRXf and TRXm basically retain the same targets while FBPase and GAPDH are exclusively activated by TRXf and not by TRXm (Collin et al., 2003; Marri et al., 2009). This suggests that monocysteinic TRX have peculiar properties distinct from the WT enzyme and/or that the loss of specificity is due to the use of high concentrations of TRX. Indeed, while enzymes show a preference for some TRX types at physiological TRX concentration, many TRX types become able to significantly activate a number of TRX targets if used at high concentration (Collin et al., 2003, 2004). By contrast, the diversity of the targets appeared to be strongly dependent on the type of protein extracts employed (organism, tissue, growth conditions...). The problem of specificity is even larger since monocysteinic GRX columns also retain the same type of targets than those bound on TRX columns (Rouhier et al., 2005; Li et al., 2007). Classical GRXs belong to the TRX family and contain an active site disulfide (Cys-Pro-Trp/Phe-Cys) that is reduced by glutathione (Rouhier et al., 2008; Zaffagnini et al., 2012c). GRXs can reduce disulfide bonds on their target proteins, although much less efficiently than TRX, but they are thought to play a more prominent role in the control of protein (de)glutathionylation (Zaffagnini et al., 2012c).

Among all putative TRX targets, more than 130 are located in chloroplasts (Lemaire et al., 2007; Lindahl and Kieselbach, 2009). The well-established targets of TRX participating directly or indirectly in the CBC were recovered by proteomic approaches (FBPase, SBPase, GAPDH, PRK, CP12, Rubisco activase). More surprisingly, all other enzymes of the CBC were also identified among putative targets, suggesting that they might all be redox regulated (Table 1). All CBC enzymes were, however, not identified within the same study, possibly because of a low coverage rate due to the use of 2D-gels and MALDI-TOF mass spectrometry in most studies. This suggests that the number of TRX targets could be significantly higher than presently known and that the combination of TRX-affinity chromatography or thiol-labeling with modern gel-free proteomic methods may reveal a much greater diversity of new potential targets of TRXs.

Nevertheless, the identification of all CBC enzymes as potential targets of TRXs suggested the existence of a complex redox control of these enzymes that may be much more sophisticated than the light-dependent regulation initially uncovered for four enzymes of the cycle. These features may allow a fine tuning of the Calvin-Benson cycle in response to environmental changes that affect ROS production and the intracellular redox state. There are two non-mutually exclusive possibilities to explain this surprising result. First, all the CBC enzymes may contain a TRXreducible disulfide bond, like the four established TRX-targets. These regulations may have been initially missed, for example, because of their low activation upon reduction (e.g., below 50\%) or because the disulfide controls enzyme properties that have not been investigated (protein stability, cooperativity between subunits, protein-protein interactions, etc.). This may be the case for phosphoglycerate kinase (PGK) which was shown to be redox regulated, possibly by TRX, in Phaeodactylum tricornutum (Bosco et al., 2012) and Synechocystis sp. PCC6803 (Tsukamoto et al., 2013). To date, none of these putative TRX dependent redox regulations have been confirmed experimentally on any other CBC enzyme. The second possibility is that these cysteines are not attacked (or reduced) by TRX because they are engaged in a disulfide bond but because they harbor another type of cysteine oxidative modification. Indeed, although TRX are efficient protein disulfide reductases, they are also playing a role in the control of other post-translational modifications including sulfenylation, nitrosylation or glutathionylation. Therefore, putative TRX targets identified by proteomic approaches may represent proteins containing diverse types of redox PTM and should therefore be considered as putative redox regulated proteins rather than proteins containing a TRX-reducible disulfide. This was demonstrated for Chlamydomonas isocitrate lyase, an enzyme of the glyoxylate cycle participating in acetate assimilation which was retained on a monocysteinic TRX affinity column (Lemaire et al., 2004). Detailed biochemical analysis of this enzyme revealed that the enzyme is strongly and reversibly inhibited by glutathionylation but does not contain any TRX-reducible disulfide bond (Bedhomme et al., 2009). We recently obtained comparable results with the Calvin-Benson enzyme triosephosphate isomerase (TPI) which does not appear to contain a regulatory disulfide but was found to undergo glutathionylation and nitrosylation in vitro (Zaffagnini et al., 2013a). Although the number of studies is more limited, mounting evidence suggests that glutathionylation and nitrosylation also control enzymes of the CBC. These recent developments are detailed in the next sections.

\section{MULTIPLE REDOX POST-TRANSLATIONAL MODIFICATIONS}

During the last decade, glutathionylation and nitrosylation have emerged as crucial PTMs playing a major role in numerous fundamental cell processes, especially cell signaling pathways (Hess et al., 2005; Besson-Bard et al., 2008; Mieyal et al., 2008; Rouhier et al., 2008; Dalle-Donne et al., 2009; Foster et al., 2009; Astier et al., 2011; Hess and Stamler, 2012; Zaffagnini et al., 2012c). 
Table 1 | Summary of redox proteomic analyses of Calvin-Benson cycle enzymes and related proteins.

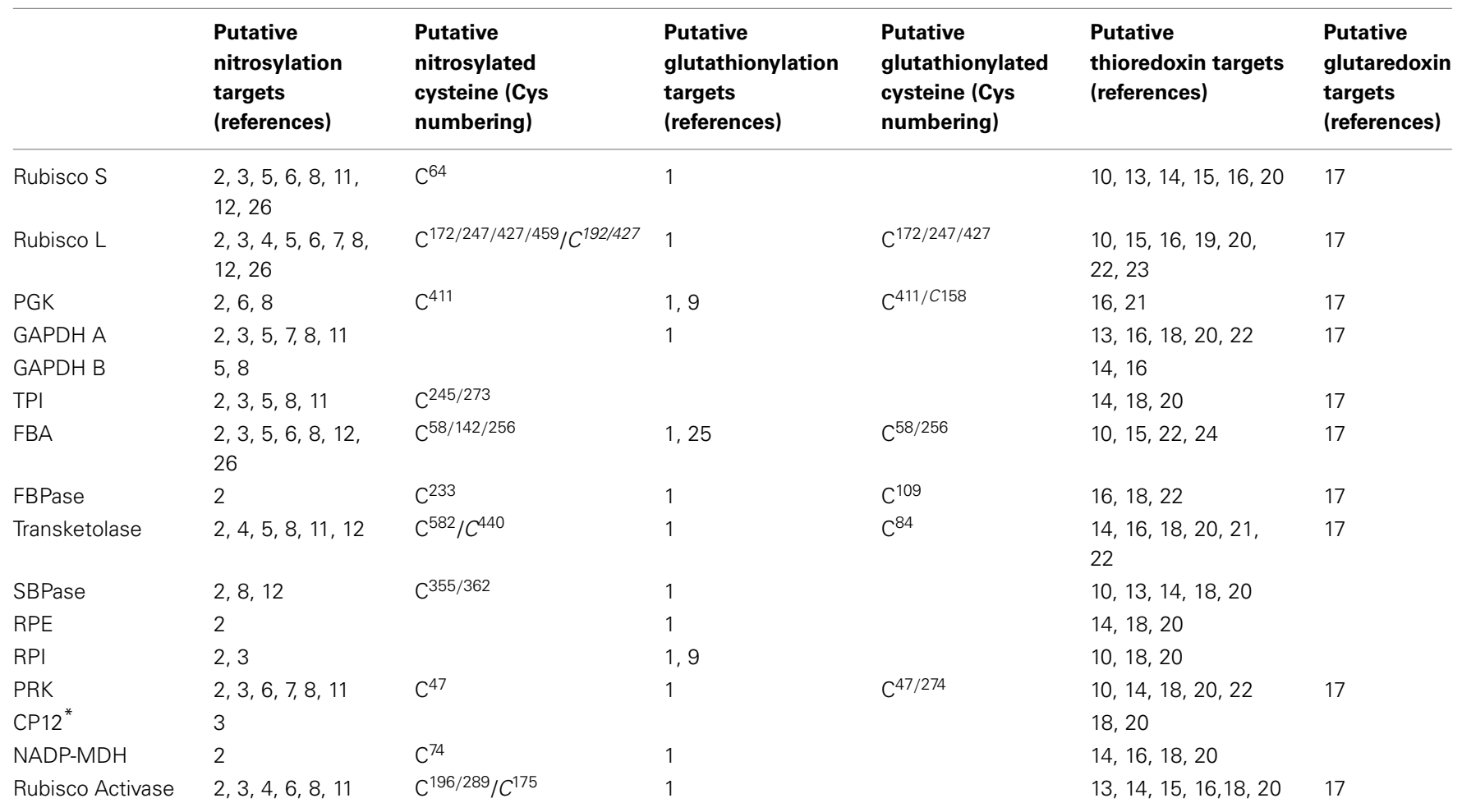

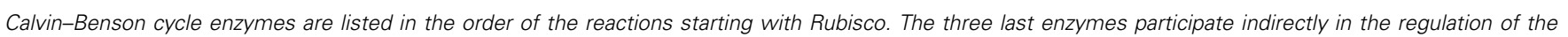

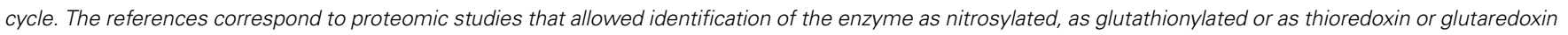

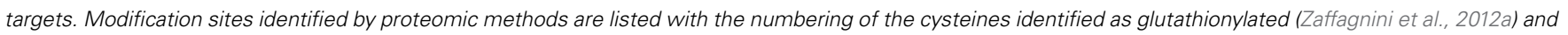

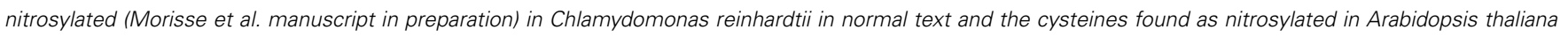

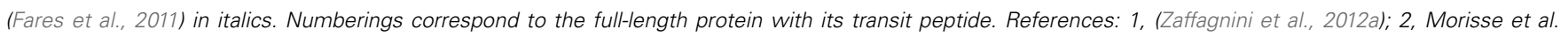

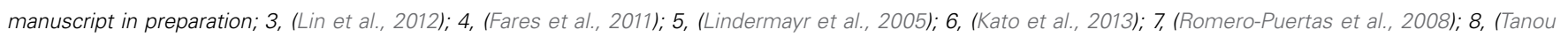
et al., 2012); 9, (Michelet et al., 2008); 10, (Lemaire et al., 2004); 11, (Tanou et al., 2009); 12, (Abat and Deswal, 2009); 13, (Motohashi et al., 2001); 14, (Balmer et al.,

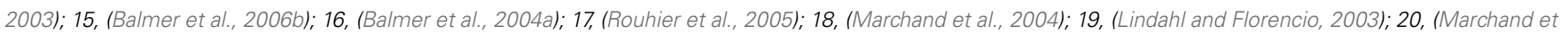
al, 2006); 21, (Balmer et al., 2006a); 22, (Pérez-Pérez et al., 2009); 23, (Hall et al., 2010); 24, (Marchand et al., 2010); 25, (Ito et al., 2003); 26, (Abat et al., 2008).

Glutathione is the major low molecular weight antioxidant in most species and exists in the reduced (GSH) and oxidized (GSSG) forms. GSH is the major form due to constant reduction of GSSG to GSH by glutathione reductase (GR) at the expense of NADPH. Glutathione is considered as a major cellular antioxidant and redox buffer but also plays an important role in a myriad of cellular and physiological functions including detoxification of heavy metals and xenobiotics, root growth or pathogen responses (Noctor et al., 2012). Glutathionylation is a post-translational modification triggered by oxidative stress conditions and consisting of the formation of a mixed-disulfide between a protein free thiol and the thiol of a molecule of glutathione. Although the precise mechanism leading to glutathionylation is still unclear in vivo, it is considered to occur mainly either through reactive oxygen species (ROS)-dependent sulfenic acid formation followed by reaction with reduced glutathione $(\mathrm{GSH})$ or by thiol/disulfide exchange with oxidized glutathione (GSSG). The reverse reaction, named deglutathionylation, is mainly catalyzed by GRXs.
Nitrosylation consists in the formation of nitrosothiols by reaction of protein thiols with nitric oxide (NO). It can be triggered chemically by reactive nitrogen species (RNS) which includes $\mathrm{NO}$ and its related species (such as the nitrosonium cation, $\mathrm{NO}^{+}$; nitroxyl anion, $\mathrm{NO}^{-}$; dinitrogen trioxide, $\mathrm{N}_{2} \mathrm{O}_{3}$ or peroxynitrite, $\mathrm{ONOO}^{-}$) but also by transnitrosylation reactions mediated by small nitrosothiols (e.g., nitrosoglutathione, GSNO) or by other nitrosylated proteins (Hogg, 2002; Hess et al., 2005; Benhar et al., 2009; Zaffagnini et al., 2013b). The reduction of nitrosothiols on proteins, i.e., denitrosylation, entails two possible mechanisms dependent on reduced glutathione (GSH) or reduced TRX (Benhar et al., 2009; Sengupta and Holmgren, 2013).

To date, several hundreds of targets of glutathionylation and nitrosylation have been identified in bacteria, yeast, animals and plants, suggesting a role for these redox modifications in many cellular processes (Mieyal et al., 2008; Astier et al., 2011; Hess and Stamler, 2012; Zaffagnini et al., 2012c; Maron et al., 2013). In our two recent studies, the use of biotin-based enrichment strategies using streptavidin affinity chromatography combined 
with up-to date mass spectrometry instruments allowed identification of 225 glutathionylated proteins and 492 nitrosylated proteins in Chlamydomonas (Zaffagnini et al., 2012a; Morisse et al. manuscript in preparation). There is a striking overlap between potential TRX targets and proteins identified as nitrosylated or glutathionylated through proteomic studies. This suggests that these proteins are regulated by multiple redox PTMs or that the methods aimed at identifying TRX targets also identified nitrosylated and glutathionylated proteins. The latter possibility is consistent with the fact that TRX was proposed to catalyze both (de)nitrosylation and (de)glutathionylation reaction for some targets (Benhar et al., 2008; Greetham et al., 2010; Bedhomme et al., 2012; Zaffagnini et al., 2013b).

Notably, all CBC enzymes appear to be modified by glutathionylation (Table 1). Proteomic studies initially reported in vivo glutathionylation for fructose-1,6-bisphosphate aldolase (FBA) in Arabidopsis (Ito et al., 2003) and for phosphoglycerate kinase (PGK) and ribose-5-phosphate isomerase (RPI) in Chlamydomonas (Michelet et al., 2008). More recently, all $\mathrm{CBC}$ enzymes were found to undergo glutathionylation in Chlamydomonas (Zaffagnini et al., 2012a, 2013a). The modifications of FBA, PGK and $\mathrm{A}_{4}-\mathrm{GAPDH}$ from Chlamydomonas were confirmed by demonstrating that the purified protein is glutathionylated after treatment with BioGSSG (biotinylated oxidized glutathione) in vitro. Chlamydomonas PRK was found to be strongly inhibited by GSSG and the activity could be fully recovered after DTT treatment (Zaffagnini et al., 2012a). The glutathionylation of different isoforms of GAPDH from Arabidopsis was investigated in detail (Zaffagnini et al., 2007). Arabidopsis $\mathrm{A}_{4}$-GAPDH was shown to be glutathionylated in vitro on its catalytic cysteine with a concomitant loss of enzyme activity. The enzyme is very sensitive to oxidants and is rapidly and irreversibly inactivated by $\mathrm{H}_{2} \mathrm{O}_{2}$. However, incubation of the enzyme with $\mathrm{H}_{2} \mathrm{O}_{2}$ in the presence of GSH leads to glutathionylation, most likely through a mechanism involving a sulfenic acid intermediate. Therefore, glutathionylation efficiently protects $\mathrm{A}_{4}$-GAPDH from irreversible oxidation and glutathionylated $A_{4}-G A P D H$ was reported to be efficiently reactivated by GRXs (Zaffagnini et al., 2008; Couturier et al., 2009; Gao et al., 2010). Similar results were reported for the cytoplasmic GAPDH isoform (GAPC) (Holtgrefe et al., 2008; Bedhomme et al., 2012). By contrast, the $\mathrm{A}_{2} \mathrm{~B}_{2}-\mathrm{GAPDH}$ isoform and its higher oligomeric state $\mathrm{A}_{8} \mathrm{~B}_{8}-\mathrm{GAPDH}$ were not found to undergo glutathionylation in vitro (Zaffagnini et al., 2007). Chlamydomonas TPI was also found to be glutathionylated in vitro but with no apparent effect on the enzyme activity (Zaffagnini et al., 2013a). Finally, glutathionylation is also likely affecting the CBC indirectly through regulation of TRXf (Michelet et al., 2005). Among all chloroplastic TRXs, TRXf from diverse species specifically undergo glutathionylation on a strictly conserved extra cysteine that is distinct from the two-active site cysteines and located in the vicinity of the active site. The glutathionylation of TRXf strongly decreases its ability to activate $\mathrm{A}_{2} \mathrm{~B}_{2}-\mathrm{GAPDH}$ and NADP-MDH likely by perturbing the interaction with FTR since glutathionylated TRXf is less efficiently reduced in the light. This suggests that glutathionylation could affect all TRXf targets which include many enzymes involved in carbon fixation and other chloroplast metabolic pathways. $\mathrm{A}_{2} \mathrm{~B}_{2}-\mathrm{GAPDH}$ being specifically activated by TRXf, GAPDH activity is likely fully down-regulated under conditions leading to protein glutathionylation in chloroplasts, such as enhanced ROS production either by direct glutathionylation of $\mathrm{A}_{4}-\mathrm{GAPDH}$ on its catalytic cysteine or indirectly through glutathionylation of TRXf that decrease the activation of $\mathrm{A}_{2} \mathrm{~B}_{2}$ GAPDH.

All CBC enzymes were also identified as nitrosylated proteins by proteomic approaches (Table 1). None of these putative regulations has been confirmed biochemically with the exception of Chlamydomonas TPI that was shown to be partially inhibited by nitrosylation (Zaffagnini et al., 2013a) and land plant Rubisco which appears to be inhibited by nitrosylation (Abat et al., 2008; Abat and Deswal, 2009). Cytosolic GAPDH was shown to be completely inhibited by nitrosylation and fully reactivated by GSH or, less efficiently, by TRXs (Holtgrefe et al., 2008; Zaffagnini et al., 2013b). These properties may likely apply to chloroplastic GAPDH considering its strong structural and biochemical similarities with cytosolic GAPDH.

Recent proteomic studies also allowed identification of the cysteine residues undergoing nitrosylation and glutathionylation (Table 1). A schematic representation of the sites identified as nitrosylated, glutathionylated or forming a TRX-reducible disulfide bond is presented in Figures 7, 8. Many of these cysteines are conserved, especially in photosynthetic organisms. Some sites are shared between different modifications while others are unique. For example, in Chlamydomonas PRK, Cys47 appears modified by the 3 types of redox PTMs while Cys274 was only found to undergo glutathionylation. By contrast, Chlamydomonas FBPase is modified on 4 distinct cysteines that are all conserved in photosynthetic organisms: the enzyme undergoes glutathionylation on Cys109, nitrosylation on Cys233 while the TRX-reducible disulfide bond is most likely located between Cys213 and Cys219 by homology with higher plant FBPase. The large subunit of Rubisco appears to undergo multiple modifications with Cys459 identified as nitrosylated and 3 cysteines (Cys172, Cys247, Cys427) undergoing both nitrosylation and glutathionylation (Table 1, Figure 7). These results are consistent with previous studies (reviewed in (Moreno et al., 2008)) that suggested a redox control of the activity and/or the stability of Rubisco involving Cys172 (Moreno and Spreitzer, 1999; Marcus et al., 2003), Cys427 (Muthuramalingam et al., 2013) or Cys 459 (Marin-Navarro and Moreno, 2006). The multiplicity of the modification sites suggest that CBC enzymes are indeed regulated by multiple redox PTMs although the different modifications may not occur at the same time, at the same site, to the same extent or under the same physiological/cellular conditions.

$\mathrm{CBC}$ enzymes appear to be regulated by an intricate network of redox PTMs whose dynamics remains to be explored. These regulations may allow a tight coupling between the activity of $\mathrm{CBC}$ enzymes and the intracellular redox state linked to environmental conditions. While dithiol/disulfide exchange reactions controlled by TRXs allow light-dependent activation of $\mathrm{CBC}$ enzymes, glutathionylation could constitute an alternative mechanism of regulation of the $\mathrm{CBC}$ pathway occurring under illumination and dependent on ROS production and glutathione. 


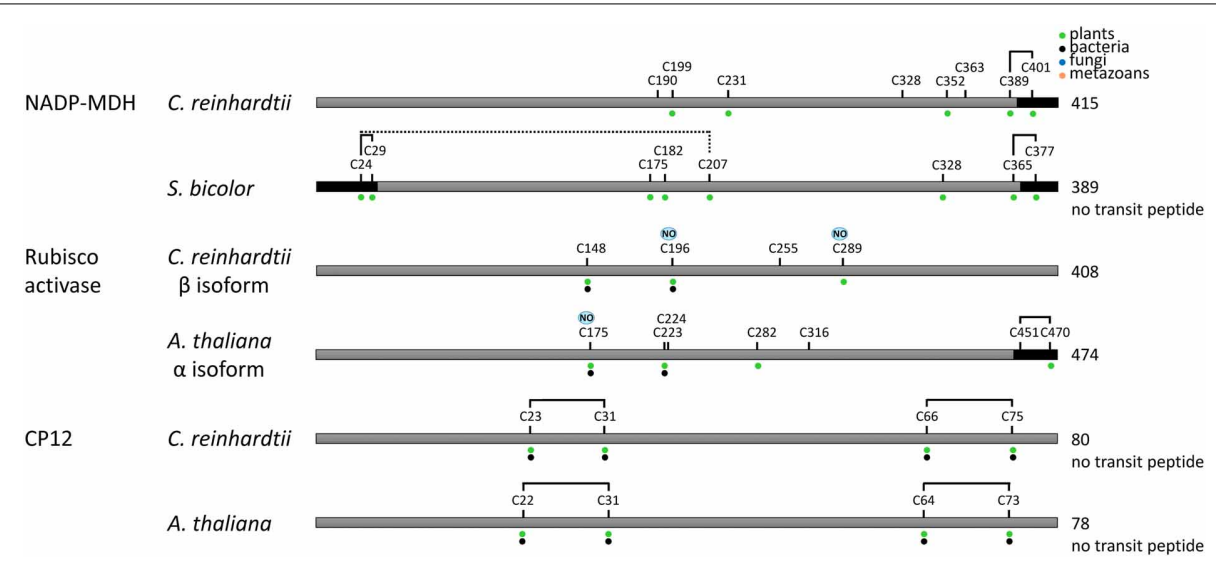

FIGURE 8 | Redox regulated cysteines in proteins controlling indirectly the Calvin-Benson cycle. All proteins are schematically represented linearly. The numbering corresponds to the sequence with the transit peptide, except when "no transit peptide" is indicated on the right. Lines between cysteines indicate confirmed (black) or suggested (black and dashed) disulfide bonds. Cysteines identified as nitrosylated and glutathionylated are labeled with NO (blue) and SG (purple), respectively. The dots indicate cysteine conservation in photosynthetic organisms (green), bacteria (black), fungi (blue) and metazoans (orange). In $A$. thaliana Rubisco activase, the regulatory cysteines Cys451 and Cys470 in the precursor correspond to Cys392 and Cys411 in the mature form. Dark boxes correspond to insertions/extension present in the TRX-regulated isoforms and absent in the isoforms not regulated by TRX.
Indeed, all available data suggest that glutathionylation downregulates the activity of numerous CBC enzymes. Therefore, it has been proposed that glutathionylation could constitute a new mechanism of regulation of photosynthetic metabolism allowing a fine tuning of the $\mathrm{CBC}$ cycle in order to redistribute reducing power (in the form of NAPDH) and energy (in the form of ATP) within chloroplasts under oxidative stress, thereby favoring ROS scavenging (Michelet et al., 2005; Lemaire et al., 2007). This redistribution may be required transiently to cope with stress conditions. Glutathionylation also constitutes a mechanism of protection of $\mathrm{CBC}$ enzymes containing highly reactive cysteines from irreversible oxidation in the presence of ROS, as demonstrated for GAPDH (Zaffagnini et al., 2007). It has also been proposed that the glutathionylation/deglutathionylation cycle catalyzed by GRXs may contribute to ROS scavenging within chloroplasts (Zaffagnini et al., 2012b). In addition to regulation of CBC enzymes, redox signaling contributes to numerous shortand long-term acclimation responses that allow plants to adapt to fluctuating environmental conditions by enabling metabolic readjustments to maintain cellular homeostasis (Scheibe and Dietz, 2012).

It should be kept in mind that redox PTMs of CBC enzymes do not necessarily imply that the modification regulates the CBC pathway. First, it is possible that the modification does not affect the activity of the protein as shown for the glutathionylation of Chlamydomonas TPI (Zaffagnini et al., 2013a). However, even if it does, the extent of the modification in vivo being undetermined, it is possible that it only affects a minor pool of the total protein (especially for abundant proteins such as those involved in the CBC) and modification of this pool may not be limiting for the pathway. Finally, numerous identified proteins may represent moonlighting proteins that, upon redox PTMs, are diverted to new functions unrelated to their metabolic role in carbon metabolism as shown for cytosolic GAPDH in mammals (Hara et al., 2005) (see Zaffagnini et al. this series).
Indeed, upon apoptotic stimulation, nitrosylation of mammalian GAPDH triggers its translocation to the nucleus where it regulates gene expression through several mechanisms including transnitrosylation of nuclear proteins (Kornberg et al., 2010). Plant cytosolic GAPDH was also shown to undergo nitrosylation and to relocalize to the nucleus under stress condition but the exact physiological function of the modification remains to be established (Holtgrefe et al., 2008; Vescovi et al., 2013; Zaffagnini et al., 2013b). Moreover, the glutathionylation of mammalian GAPDH has been shown to regulate endothelin1 (ET-1) expression by altering the binding of GAPDH to the $3^{\prime}$ untranslated region of ET-1 mRNA thereby increasing its stability and resulting in increased ET-1 protein levels and endothelial vasoconstriction (Rodriguez-Pascual et al., 2008). The only $\mathrm{CBC}$ enzyme for which a moonlighting function has been reported is Rubisco. Indeed, under oxidative stress the Rubisco holoenzyme, composed of 8 small subunits (SSU) and 8 large subunits (LSU) disassembles into its constituents and LSU subsequently binds chloroplast mRNAs non-specifically and forms large particles (Yosef et al., 2004; Knopf and Shapira, 2005; Cohen et al., 2006). Recently, Chlamydomonas LSU but not SSU was shown to accumulate in chloroplast stress granules (cpSGs) under oxidative stress conditions (Uniacke and Zerges, 2008). cpSGs are RNA granules related to mammalian stress granules that form during oxidative stress and disassemble during recovery from stress. This study therefore suggested a novel function of Rubisco LSU as an mRNA-localizing and assembly factor of cpSGs (Uniacke and Zerges, 2008). This moonlighting function being triggered by oxidative stress conditions, it may likely be regulated by redox PTMs. Since cysteine modifications control several moonlighting functions of cytosolic GAPDH, the same may be true for chloroplastic GAPDH isoforms participating in the $\mathrm{CBC}$ which also undergo multiple redox PTMs. These redox PTMs are likely to play an important role in ROS sensing and to allow adaptation or alternatively 
trigger programmed cell death under varying environmental conditions.

\section{CONCLUDING REMARKS}

Recent proteomic studies suggest that CBC enzymes undergo multiple types of redox PTMs including nitrosylation, glutathionylation and oxido-reduction of disulfide bonds. The possible regulations by additional redox PTMs whose importance starts to emerge in non-photosynthetic organisms, such as sulfenylation, sulfhydration or cysteinylation, will also have to be explored. Many data also suggest the existence of a strong interplay between the different types of redox PTMs as recently described for nitrosylation and glutathionylation (Zaffagnini et al., 2012c). All these data suggest that CBC enzymes are regulated by a complex and highly dynamic network of redox PTMs. Unraveling the importance and function of these redox modifications under diverse physiological and growth conditions and characterizing the underlying molecular and structural determinants will certainly constitute a major challenge for future studies. Acquiring this knowledge is highly desirable considering the central role of the $\mathrm{CBC}$ in the determination of crop yields, $\mathrm{CO}_{2}$ fixation, biomass and biofuel production and plant adaptation to stress conditions.

\section{ACKNOWLEDGMENTS}

This work was supported in part by Agence Nationale de la Recherche Grant 09-BLAN-0005-ROSSIGNAL and LABEX DYNAMO ANR-11-LABX-0011. MEPP was supported by an IEF EU Marie Curie Fellowship.

\section{REFERENCES}

Abat, J. K., and Deswal, R. (2009). Differential modulation of Snitrosoproteome of Brassica juncea by low temperature: change in S-nitrosylation of Rubisco is responsible for the inactivation of its carboxylase activity. Proteomics 9, 4368-4380. doi: 10.1002/pmic. 200800985

Abat, J. K., Mattoo, A. K., and Deswal, R. (2008). S-nitrosylated proteins of a medicinal CAM plant Kalanchoe pinnata- ribulose-1,5-bisphosphate carboxylase/oxygenase activity targeted for inhibition. FEBS J. 275, 2862-2872. doi: 10.1111/j.1742-4658.2008.06425.x

Anderson, L. E. (1973a). Dithiothreitol activation of some chloroplast enzymes in extracts of etiolated pea seedlings. Plant Sci. Lett. 1, 331-334. doi: 10.1016/03044211(73)90098-9

Anderson, L. E. (1973b). Regulation of pea leaf ribulose-5-phosphate kinase activity. Biochim. Biophys. Acta 321, 484-488. doi: 10.1016/0005-2744 (73)90190-3

Anderson, L. E. (1974). Activation of pea leaf chloroplast sedoheptulose 1,7diphosphate phosphatase by light and dithiothreitol. Biochem. Biophys. Res. Commun. 59, 907-913. doi: 10.1016/S0006-291X(74)80065-3

Anderson, L. E., and Avron, M. (1976). Light modulation of enzyme activity in chloroplasts: generation of membrane-bound vicinal-dithiol groups by photosynthetic electron transport. Plant Physiol. 57, 209-213. doi: 10.1104/pp.57.2.209

Anderson, L. E., and Lim, T. C. (1972). Chloroplast glyceraldehyde 3-phosphate dehydrogenase: light-dependent change in the enzyme. FEBS Lett. 27, 189-191. doi: 10.1016/0014-5793(72)80616-1

Arsova, B., Hoja, U., Wimmelbacher, M., Greiner, E., Ustun, S., Melzer, M., et al. (2010). Plastidial thioredoxin $\mathrm{z}$ interacts with two fructokinase-like proteins in a thiol-dependent manner: evidence for an essential role in chloroplast development in Arabidopsis and Nicotiana benthamiana. Plant Cell 22, 1498-1515. doi: 10.1105/tpc.109.071001
Astier, J., Rasul, S., Koen, E., Manzoor, H., Besson-Bard, A., Lamotte, O., et al. (2011). S-nitrosylation: an emerging post-translational protein modification in plants. Plant. Sci. 181, 527-533. doi: 10.1016/j.plantsci.2011.02.011

Austin, P. A., Stuart Ross, I., and Mills, J. D. (1992). Light/dark regulation of photosynthetic enzymes within intact cells of the cyanobacterium Nostoc sp. Mac. Biochim. Biophys. Acta 1099, 226-232. doi: 10.1016/0005-2728(92)90031-V

Avilan, L., Gontero, B., Lebreton, S., and Ricard, J. (1997). Memory and imprinting effects in multienzyme complexes-I. Isolation, dissociation, and reassociation of a phosphoribulokinase-glyceraldehyde-3-phosphate dehydrogenase complex from Chlamydomonas reinhardtii chloroplasts. Eur. J. Biochem. 246, 78-84. doi: 10.1111/j.1432-1033.1997.00078.x

Avron, M., and Gibbs, M. (1974). Properties of phosphoribulokinase of whole chloroplasts. Plant Physiol. 53, 136-139. doi: 10.1104/pp.53.2.136

Baalmann, E., Backhausen, J. E., Kitzmann, C., and Scheibe, R. (1994). Regulation of NADP-dependent glyceraldehyde 3-phosphate dehydrogenase activity in spinach chloroplasts. Bot. Acta 107, 313-320.

Baalmann, E., Scheibe, R., Cerff, R., and Martin, W. (1996). Functional studies of chloroplast glyceraldehyde-3-phosphate dehydrogenase subunits A and B expressed in Escherichia coli: formation of highly active A4 and B4 homotetramers and evidence that aggregation of the B4 complex is mediated by the B subunit carboxy terminus. Plant Mol. Biol. 32, 505-513. doi: 10.1007/BF00019102

Baier, D., and Latzko, E. (1975). Properties and regulation of C-1-fructose-1,6diphosphatase from spinach chloroplasts. Biochim. Biophys. Acta 396, 141-148. doi: 10.1016/0005-2728(75)90197-8

Ballicora, M. A., Frueauf, J. B., Fu, Y., Schürmann, P., and Preiss, J. (2000). Activation of the potato tuber ADP-glucose pyrophosphorylase by thioredoxin. J. Biol. Chem. 275, 1315-1320. doi: 10.1074/jbc.275.2.1315

Balmer, Y., Koller, A., Del Val, G., Manieri, W., Schürmann, P., and Buchanan, B. B. (2003). Proteomics gives insight into the regulatory function of chloroplast thioredoxins. Proc. Natl. Acad. Sci. U.S.A. 100, 370-375. doi: 10.1073/pnas.232703799

Balmer, Y., Koller, A., Val, G. D., Schürmann, P., and Buchanan, B. B. (2004a). Proteomics uncovers proteins interacting electrostatically with thioredoxin in chloroplasts. Photosynth. Res. 79, 275-280. doi: 10.1023/B:PRES.0000017207.88257.d4

Balmer, Y., Vensel, W. H., Tanaka, C. K., Hurkman, W. J., Gelhaye, E., Rouhier, N., et al. (2004b). Thioredoxin links redox to the regulation of fundamental processes of plant mitochondria. Proc. Natl. Acad. Sci. U.S.A. 101, 2642-2647. doi: 10.1073/pnas.0308583101

Balmer, Y., Vensel, W. H., Cai, N., Manieri, W., Schürmann, P., Hurkman, W. J., et al. (2006a). A complete ferredoxin/thioredoxin system regulates fundamental processes in amyloplasts. Proc. Natl. Acad. Sci. U.S.A. 103, 2988-2993. doi: 10.1073/pnas.0511040103

Balmer, Y., Vensel, W. H., Hurkman, W. J., and Buchanan, B. B. (2006b). Thioredoxin target proteins in chloroplast thylakoid membranes. Antioxid. Redox Signal. 8, 1829-1834. doi: 10.1089/ars.2006.8.1829

Bassham, J. A. (1971). Photosynthetic carbon metabolism. Proc. Natl. Acad. Sci. U.S.A. 68, 2877-2882. doi: 10.1073/pnas.68.11.2877

Bassham, J. A., Benson, A. A., and Calvin, M. (1950). The path of carbon in photosynthesis. J. Biol. Chem. 185, 781-787.

Bedhomme, M., Adamo, M., Marchand, C. H., Couturier, J., Rouhier, N., Lemaire, S. D., et al. (2012). Glutathionylation of cytosolic glyceraldehyde-3-phosphate dehydrogenase from the model plant Arabidopsis thaliana is reversed by both glutaredoxins and thioredoxins in vitro. Biochem. J. 445, 337-347. doi: 10.1042/BJ20120505

Bedhomme, M., Zaffagnini, M., Marchand, C. H., Gao, X. H., Moslonka-Lefebvre, M., Michelet, L., et al. (2009). Regulation by glutathionylation of isocitrate lyase from Chlamydomonas reinhardtii. J. Biol. Chem. 284, 36282-36291. doi: 10.1074/jbc.M109.064428

Benhar, M., Forrester, M. T., Hess, D. T., and Stamler, J. S. (2008). Regulated protein denitrosylation by cytosolic and mitochondrial thioredoxins. Science 320, 1050-1054. doi: 10.1126/science. 1158265

Benhar, M., Forrester, M. T., and Stamler, J. S. (2009). Protein denitrosylation: enzymatic mechanisms and cellular functions. Nat. Rev. Mol. Cell Biol. 10, 721-732. doi: 10.1038/nrm2764

Besson-Bard, A., Pugin, A., and Wendehenne, D. (2008). New insights into nitric oxide signaling in plants. Annu. Rev. Plant Biol. 59, 21-39. doi: 10.1146/annurev.arplant.59.032607.092830 
Blankenship, R. (2002). Molecular Mechanisms of Photosynthesis. Oxford: Blackwell Science Ltd. doi: 10.1002/9780470758472

Bohrer, A. S., Massot, V., Innocenti, G., Reichheld, J. P., Issakidis-Bourguet, E., and Vanacker, H. (2012). New insights into the reduction systems of plastidial thioredoxins point out the unique properties of thioredoxin $\mathrm{z}$ from Arabidopsis. J. Exp. Bot. 63, 6315-6323. doi: 10.1093/jxb/ers283

Bosco, M. B., Aleanzi, M. C., and Iglesias, A. A. (2012). Plastidic phosphoglycerate kinase from Phaeodactylum tricornutum: on the critical role of cysteine residues for the enzyme function. Protist 163, 188-203. doi: 10.1016/j.protis.2011.07.001

Brandes, H. K., Larimer, F. W., and Hartman, F. C. (1996). The molecular pathway for the regulation of phosphoribulokinase by thioredoxin f. J. Biol. Chem. 271, 3333-3335. doi: 10.1074/jbc.271.7.3333

Broin, M., Cuine, S., Eymery, F., and Rey, P. (2002). The plastidic 2-cysteine peroxiredoxin is a target for a thioredoxin involved in the protection of the photosynthetic apparatus against oxidative damage. Plant Cell 14, 1417-1432. doi: 10.1105/tpc.001644

Buchanan, B. B. (1980). Role of light in the regulation of chloroplast enzymes. Annu. Rev. Plant Physiol. 31, 341-374. doi: 10.1146/annurev.pp.31.060180.002013

Buchanan, B. B. (1991). Regulation of $\mathrm{CO} 2$ assimilation in oxygenic photosynthesis: the ferredoxin/thioredoxin system. Perspective on its discovery, present status, and future development. Arch. Biochem. Biophys. 288, 1-9. doi: 10.1016/0003-9861(91)90157-E

Buchanan, B. B., Gruissem, W., and Jones, R. L. (2002a). Biochemistry and Molecular Biology of Plants. Somerset: Wiley.

Buchanan, B. B., Schürmann, P., Wolosiuk, R. A., and Jacquot, J. P. (2002b). The ferredoxin/thioredoxin system: from discovery to molecular structures and beyond. Photosynth. Res. 73, 215-222. doi: 10.1023/A:1020407432008

Buchanan, B. B., Holmgren, A., Jacquot, J. P., and Scheibe, R. (2012). Fifty years in the thioredoxin field and a bountiful harvest. Biochim. Biophys. Acta 1820, 1822-1829. doi: 10.1016/j.bbagen.2012.07.006

Carmo-Silva, A. E., Marri, L., Sparla, F., and Salvucci, M. E. (2011). Isolation and compositional analysis of a CP12-associated complex of calvin cycle enzymes from Nicotiana tabacum. Protein Pept. Lett. 18, 618-624. doi: 10.2174/092986611795222740

Carmo-Silva, A. E., and Salvucci, M. E. (2013). The regulatory properties of Rubisco activase differ among species and affect photosynthetic induction during light transitions. Plant Physiol. 161, 1645-1655. doi: 10.1104/pp.112.213348

Carr, P. D., Verger, D., Ashton, A. R., and Ollis, D. L. (1999). Chloroplast NADPmalate dehydrogenase: structural basis of light-dependent regulation of activity by thiol oxidation and reduction. Structure 7, 461-475. doi: 10.1016/S09692126(99)80058-6

Cerff, R. (1978). Glyceraldehyde-3-phosphate dehydrogenase (NADP) from Sinapis alba $L$. NAD $(\mathrm{P})$-induced conformation changes of the enzyme. Eur. J. Biochem. 82, 45-53. doi: 10.1111/j.1432-1033.1978.tb11995.x

Champigny, M.-L., and Bismuth, E. (1976). Role of photosynthetic electron transfer in light activation of calvin cycle enzymes. Physiol. Plant 36, 95-100. doi: 10.1111/j.1399-3054.1976.tb05034.x

Chiadmi, M., Navaza, A., Miginiac-Maslow, M., Jacquot, J. P., and Cherfils, J. (1999). Redox signalling in the chloroplast: structure of oxidized pea fructose-1,6-bisphosphate phosphatase. EMBO J. 18, 6809-6815. doi: 10.1093/emboj/18.23.6809

Chibani, K., Tarrago, L., Schürmann, P., Jacquot, J. P., and Rouhier, N. (2011). Biochemical properties of poplar thioredoxin z. FEBS Lett. 585, 1077-1081. doi: 10.1016/j.febslet.2011.03.006

Chibani, K., Wingsle, G., Jacquot, J. P., Gelhaye, E., and Rouhier, N. (2009). Comparative genomic study of the thioredoxin family in photosynthetic organisms with emphasis on Populus trichocarpa. Mol. Plant 2, 308-322. doi: $10.1093 / \mathrm{mp} / \mathrm{ssn} 076$

Cohen, I., Sapir, Y., and Shapira, M. (2006). A conserved mechanism controls translation of Rubisco large subunit in different photosynthetic organisms. Plant Physiol. 141, 1089-1097. doi: 10.1104/pp.106.079046

Collin, V., Issakidis-Bourguet, E., Marchand, C., Hirasawa, M., Lancelin, J. M., Knaff, D. B., et al. (2003). The Arabidopsis plastidial thioredoxins: new functions and new insights into specificity. J. Biol. Chem. 278, 23747-23752. doi: 10.1074/jbc.M302077200

Collin, V., Lamkemeyer, P., Miginiac-Maslow, M., Hirasawa, M., Knaff, D. B., Dietz, K. J., et al. (2004). Characterization of plastidial thioredoxins from
Arabidopsis belonging to the new y-type. Plant Physiol. 136, 4088-4095. doi: 10.1104/pp.104.052233

Courteille, A., Vesa, S., Sanz-Barrio, R., Cazale, A. C., Becuwe-Linka, N., Farran, I., et al. (2013). Thioredoxin $\mathrm{m} 4$ controls photosynthetic alternative electron pathways in Arabidopsis. Plant Physiol. 161, 508-520. doi: 10.1104/pp.112. 207019

Couturier, J., Koh, C. S., Zaffagnini, M., Winger, A. M., Gualberto, J. M., Corbier, C., et al. (2009). Structure-function relationship of the chloroplastic glutaredoxin S12 with an atypical WCSYS active site. J. Biol. Chem. 284, 9299-9310. doi: 10.1074/jbc.M807998200

Dai, S., Friemann, R., Glauser, D. A., Bourquin, F., Manieri, W., Schürmann, P., et al. (2007). Structural snapshots along the reaction pathway of ferredoxinthioredoxin reductase. Nature 448, 92-96. doi: 10.1038/nature05937

Dai, S., Johansson, K., Miginiac-Maslow, M., Schürmann, P., and Eklund, H. (2004). Structural basis of redox signaling in photosynthesis: structure and function of ferredoxin:thioredoxin reductase and target enzymes. Photosynth. Res. 79, 233-248. doi: 10.1023/B:PRES.0000017194.34167.6d

Dalle-Donne, I., Rossi, R., Colombo, G., Giustarini, D., and Milzani, A. (2009). Protein S-glutathionylation: a regulatory device from bacteria to humans. Trends Biochem. Sci. 34, 85-96. doi: 10.1016/j.tibs.2008.11.002

Dietz, K. J. (2011). Peroxiredoxins in plants and cyanobacteria. Antioxid. Redox Signal. 15, 1129-1159. doi: 10.1089/ars.2010.3657

Dunford, R., Durrant, M., Catley, M., and Dyer, T. (1998). Location of the redoxactive cysteines in chloroplast sedoheptulose-1,7-bisphosphatase indicates that its allosteric regulation is similar but not identical to that of fructose-1,6bisphosphatase. Photosynth. Res. 58, 221-230. doi: 10.1023/A:1006178826976

Erales, J., Mekhalfi, M., Woudstra, M., and Gontero, B. (2011). Molecular mechanism of NADPH-glyceraldehyde-3-phosphate dehydrogenase regulation through the C-terminus of CP12 in Chlamydomonas reinhardtii. Biochemistry 50, 2881-2888. doi: 10.1021/bi1020259

Falini, G., Fermani, S., Ripamonti, A., Sabatino, P., Sparla, F., Pupillo, P., et al. (2003). Dual coenzyme specificity of photosynthetic glyceraldehyde3-phosphate dehydrogenase interpreted by the crystal structure of A4 isoform complexed with NAD. Biochemistry 42, 4631-4639. doi: 10.1021/ bi0272149

Fares, A., Rossignol, M., and Peltier, J. B. (2011). Proteomics investigation of endogenous S-nitrosylation in Arabidopsis. Biochem. Biophys. Res. Commun. 416, 331-336. doi: 10.1016/j.bbrc.2011.11.036

Fermani, S., Ripamonti, A., Sabatino, P., Zanotti, G., Scagliarini, S., Sparla, F., et al. (2001). Crystal structure of the non-regulatory A(4)isoform of spinach chloroplast glyceraldehyde-3-phosphate dehydrogenase complexed with NADP. J. Mol. Biol. 314, 527-542. doi: 10.1006/jmbi.2001.5172

Fermani, S., Sparla, F., Falini, G., Martelli, P. L., Casadio, R., Pupillo, P., et al. (2007). Molecular mechanism of thioredoxin regulation in photosynthetic A2B2-glyceraldehyde-3-phosphate dehydrogenase. Proc. Natl. Acad. Sci. U.S.A. 104, 11109-11114. doi: 10.1073/pnas.0611636104

Fermani, S., Trivelli, X., Sparla, F., Thumiger, A., Calvaresi, M., Marri, L., et al. (2012). Conformational selection and folding-upon-binding of intrinsically disordered protein $\mathrm{CP} 12$ regulate photosynthetic enzymes assembly. J. Biol. Chem. 287, 21372-21383. doi: 10.1074/jbc.M112.350355

Foster, M. W., Hess, D. T., and Stamler, J. S. (2009). Protein S-nitrosylation in health and disease: a current perspective. Trends Mol. Med. 15, 391-404. doi: 10.1016/j.molmed.2009.06.007

Foyer, C. H., Bloom, A. J., Queval, G., and Noctor, G. (2009). Photorespiratory metabolism: genes, mutants, energetics, and redox signaling. Annu. Rev. Plant Biol. 60, 455-484. doi: 10.1146/annurev.arplant. 043008.091948

Foyer, C. H., and Noctor, G. (2005). Redox homeostasis and antioxidant signaling: a metabolic interface between stress perception and physiological responses. Plant Cell 17, 1866-1875. doi: 10.1105/tpc.105.033589

Gao, X. H., Zaffagnini, M., Bedhomme, M., Michelet, L., Cassier-Chauvat, C., Decottignies, P., et al. (2010). Biochemical characterization of glutaredoxins from Chlamydomonas reinhardtii: kinetics and specificity in deglutathionylation reactions. FEBS Lett. 584, 2242-2248. doi: 10.1016/j.febslet. 2010.04.034

Geigenberger, P., Kolbe, A., and Tiessen, A. (2005). Redox regulation of carbon storage and partitioning in response to light and sugars. J. Exp. Bot. 56, 1469-1479. doi: $10.1093 / \mathrm{jxb} / \mathrm{eri1} 18$ 
Goyer, A., Haslekas, C., Miginiac-Maslow, M., Klein, U., Le Maréchal, P., Jacquot, J. P., et al. (2002). Isolation and characterization of a thioredoxin-dependent peroxidase from Chlamydomonas reinhardtii. Eur. J. Biochem. 269, 272-282. doi: 10.1046/j.0014-2956.2001.02648.x

Graciet, E., Gans, P., Wedel, N., Lebreton, S., Camadro, J. M., and Gontero, B. (2003). The small protein CP12: a protein linker for supramolecular complex assembly. Biochemistry 42, 8163-8170. doi: 10.1021/bi034474x

Graciet, E., Lebreton, S., and Gontero, B. (2004). Emergence of new regulatory mechanisms in the Benson-Calvin pathway via protein-protein interactions: a glyceraldehyde-3-phosphate dehydrogenase/CP12/phosphoribulokinase complex. J. Exp. Bot. 55, 1245-1254. doi: 10.1093/jxb/erh107

Greetham, D., Vickerstaff, J., Shenton, D., Perrone, G. G., Dawes, I. W., and Grant, C. M. (2010). Thioredoxins function as deglutathionylase enzymes in the yeast Saccharomyces cerevisiae. BMC Biochem. 11:3. doi: 10.1186/14712091-11-3

Groben, R., Kaloudas, D., Raines, C. A., Offmann, B., Maberly, S. C., and Gontero, B. (2010). Comparative sequence analysis of CP12, a small protein involved in the formation of a Calvin cycle complex in photosynthetic organisms. Photosynth. Res. 103, 183-194. doi: 10.1007/s11120-010-9542-z

Hall, M., Mata-Cabana, A., Akerlund, H. E., Florencio, F. J., Schroder, W. P., Lindahl, M., et al. (2010). Thioredoxin targets of the plant chloroplast lumen and their implications for plastid function. Proteomics 10, 987-1001. doi: 10.1002/pmic.200900654

Hanke, G. T., Kimata-Ariga, Y., Taniguchi, I., and Hase, T. (2004). A post genomic characterization of Arabidopsis ferredoxins. Plant Physiol. 134, 255-264. doi: 10.1104/pp.103.032755

Hara, M. R., Agrawal, N., Kim, S. F., Cascio, M. B., Fujimuro, M., Ozeki, Y., et al. (2005). S-nitrosylated GAPDH initiates apoptotic cell death by nuclear translocation following Siah1 binding. Nat. Cell Biol. 7, 665-674. doi: 10.1038/ ncb 1268

Harrison, D. H., Runquist, J. A., Holub, A., and Miziorko, H. M. (1998). The crystal structure of phosphoribulokinase from Rhodobacter sphaeroides reveals a fold similar to that of adenylate kinase. Biochemistry 37, 5074-5085. doi: 10.1021/bi972805y

Hertle, A. P., Blunder, T., Wunder, T., Pesaresi, P., Pribil, M., Armbruster, U., et al. (2013). PGRL1 is the elusive ferredoxin-plastoquinone reductase in photosynthetic cyclic electron flow. Mol. Cell 49, 511-523. doi: 10.1016/j.molcel.2012.11.030

Hess, D. T., Matsumoto, A., Kim, S. O., Marshall, H. E., and Stamler, J. S. (2005). Protein S-nitrosylation: purview and parameters. Nat. Rev. Mol. Cell Biol. 6, 150-166. doi: 10.1038/nrm1569

Hess, D. T., and Stamler, J. S. (2012). Regulation by S-nitrosylation of protein post-translational modification. J. Biol. Chem. 287, 4411-4418. doi: 10.1074/jbc.R111.285742

Hirasawa, M., Ruelland, E., Schepens, I., Issakidis-Bourguet, E., MiginiacMaslow, M., and Knaff, D. B. (2000). Oxidation-reduction properties of the regulatory disulfides of sorghum chloroplast nicotinamide adenine dinucleotide phosphate-malate dehydrogenase. Biochemistry 39, 3344-3350. doi: 10.1021/bi9916731

Hirasawa, M., Schürmann, P., Jacquot, J. P., Manieri, W., Jacquot, P., Keryer, E., et al. (1999). Oxidation-reduction properties of chloroplast thioredoxins, ferredoxin:thioredoxin reductase, and thioredoxin f-regulated enzymes. Biochemistry 38, 5200-5205. doi: 10.1021/bi982783v

Hogg, N. (2002). The biochemistry and physiology of Snitrosothiols. Annu. Rev. Pharmacol. Toxicol. 42, 585-600. doi: 10.1146/annurev.pharmtox.42.092501.104328

Holtgrefe, S., Gohlke, J., Starmann, J., Druce, S., Klocke, S., Altmann, B., et al. (2008). Regulation of plant cytosolic glyceraldehyde 3-phosphate dehydrogenase isoforms by thiol modifications. Physiol. Plant 133, 211-228. doi: 10.1111/j.1399-3054.2008.01066.x

Hosoya-Matsuda, N., Motohashi, K., Yoshimura, H., Nozaki, A., Inoue, K., Ohmori, M., et al. (2005). Anti-oxidative stress system in cyanobacteria. Significance of type II peroxiredoxin and the role of 1-Cys peroxiredoxin in Synechocystis sp. strain PCC 6803. J. Biol. Chem. 280, 840-846. doi: 10.1074/jbc.M411493200

Howard, T. P., Fryer, M. J., Singh, P., Metodiev, M., Lytovchenko, A., Obata, T., et al. (2011a). Antisense suppression of the small chloroplast protein CP12 in tobacco alters carbon partitioning and severely restricts growth. Plant Physiol. 157, 620-631. doi: 10.1104/pp.111.183806
Howard, T. P., Lloyd, J. C., and Raines, C. A. (2011b). Inter-species variation in the oligomeric states of the higher plant Calvin cycle enzymes glyceraldehyde-3phosphate dehydrogenase and phosphoribulokinase. J. Exp. Bot. 62, 3799-3805. doi: 10.1093/jxb/err057

Howard, T. P., Metodiev, M., Lloyd, J. C., and Raines, C. A. (2008). Thioredoxinmediated reversible dissociation of a stromal multiprotein complex in response to changes in light availability. Proc. Natl. Acad. Sci. U.S.A. 105, 4056-4061. doi: 10.1073/pnas.0710518105

Huber, S. C. (1978). Substrates and inorganic phosphate control: the light activation of NADP-glyceraldehyde-3-phosphate dehydrogenase and phosphoribulokinase in barley (Hordeum vulgare) chloroplasts. FEBS Lett. 92, 12-16. doi: 10.1016/0014-5793(78)80710-8

Hutchison, R. S., Groom, Q., and Ort, D. R. (2000). Differential effects of chillinginduced photooxidation on the redox regulation of photosynthetic enzymes. Biochemistry 39, 6679-6688. doi: 10.1021/bi0001978

Issakidis, E., Decottignies, P., and Miginiac-Maslow, M. (1993). A thioredoxinindependent fully active NADP-malate dehydrogenase obtained by sitedirected mutagenesis. FEBS Lett. 321, 55-58. doi: 10.1016/0014-5793 (93) $80620-\mathrm{A}$

Issakidis, E., Lemaire, M., Decottignies, P., Jacquot, J. P., and Miginiac-Maslow, M. (1996). Direct evidence for the different roles of the $\mathrm{N}$ - and C-terminal regulatory disulfides of sorghum leaf NADP-malate dehydrogenase in its activation by reduced thioredoxin. FEBS Lett. 392, 121-124. doi: 10.1016/00145793(96)00801-0

Issakidis, E., Miginiac-Maslow, M., Decottignies, P., Jacquot, J. P., Cretin, C., and Gadal, P. (1992). Site-directed mutagenesis reveals the involvement of an additional thioredoxin-dependent regulatory site in the activation of recombinant sorghum leaf NADP-malate dehydrogenase. J. Biol. Chem. 267, 21577-21583.

Issakidis, E., Saarinen, M., Decottignies, P., Jacquot, J. P., Cretin, C., Gadal, P., et al. (1994). Identification and characterization of the second regulatory disulfide bridge of recombinant sorghum leaf NADP-malate dehydrogenase. J. Biol. Chem. 269, 3511-3517.

Issakidis-Bourguet, E., Lavergne, D., Trivelli, X., Decottignies, P., and MiginiacMaslow, M. (2006). Transferring redox regulation properties from sorghum NADP-malate dehydrogenase to Thermus NAD-malate dehydrogenase. Photosynth. Res. 89, 213-223. doi: 10.1007/s11120-006-9094-4

Ito, H., Iwabuchi, M., and Ogawa, K. (2003). The sugar-metabolic enzymes aldolase and triose-phosphate isomerase are targets of glutathionylation in Arabidopsis thaliana: detection using biotinylated glutathione. Plant Cell Physiol. 44, 655-660. doi: 10.1093/pcp/pcg098

Jacquot, J.-P., Vidal, J., Gadal, P., and Schürmann, P. (1978). Evidence for the existence of several enzyme-specific thioredoxins in plants. FEBS Lett. 96, 243-246. doi: 10.1016/0014-5793(78)80410-4

Jacquot, J. P., Lopez-Jaramillo, J., Chueca, A., Cherfils, J., Lemaire, S., Chedozeau, B., et al. (1995). High-level expression of recombinant pea chloroplast fructose1,6-bisphosphatase and mutagenesis of its regulatory site. Eur. J. Biochem. 229, 675-681. doi: 10.1111/j.1432-1033.1995.tb20513.x

Jacquot, J. P., Lopez-Jaramillo, J., Miginiac-Maslow, M., Lemaire, S., Cherfils, J., Chueca, A., et al. (1997). Cysteine-153 is required for redox regulation of pea chloroplast fructose-1,6-bisphosphatase. FEBS Lett. 401, 143-147. doi: 10.1016/S0014-5793(96)01459-7

Johansson, K., Ramaswamy, S., Saarinen, M., Lemaire-Chamley, M., IssakidisBourguet, E., Miginiac-Maslow, M., et al. (1999). Structural basis for light activation of a chloroplast enzyme: the structure of sorghum NADPmalate dehydrogenase in its oxidized form. Biochemistry 38, 4319-4326. doi: $10.1021 /$ bi982876c

Johnson, H. S. (1971). NADP-malate dehydrogenase: photoactivation in leaves of plants with Calvin cycle photosynthesis. Biochem. Biophys. Res. Commun. 43, 703-709. doi: 10.1016/0006-291X(71)90672-3

Johnson, H. S., and Hatch, M. D. (1970). Properties and regulation of leaf nicotinamide-adenine dinucleotide phosphate-malate dehydrogenase and 'malic' enzyme in plants with the C4-dicarboxylic acid pathway of photosynthesis. Biochem. J. 119, 273-280.

Kaaki, W., Woudstra, M., Gontero, B., and Halgand, F. (2013). Exploration of CP12 conformational changes and of quaternary structural properties using electrospray ionization traveling wave ion mobility mass spectrometry. Rapid Commun. Mass Spectrom. 27, 179-186. doi: 10.1002/rcm.6442 
Kato, H., Takemoto, D., and Kawakita, K. (2013). Proteomic analysis of Snitrosylated proteins in potato plant. Physiol. Plant 148, 371-386. doi: 10.1111/j.1399-3054.2012.01684.x

Kelly, G. J., Zimmermann, G., and Latzko, E. (1976). Light induced activation of fructose-1, 6-bisphosphatase in isolated intact chloroplasts. Biochem. Biophys. Res. Commun. 70, 193-199. doi: 10.1016/0006-291X(76)91127-X

Keown, J. R., Griffin, M. D., Mertens, H. D., and Pearce, F. G. (2013). Small oligomers of ribulose-bisphosphate carboxylase/oxygenase (Rubisco) activase are required for biological activity. J. Biol. Chem. 288, 20607-20615. doi: 10.1074/jbc.M113.466383

Knopf, J. A., and Shapira, M. (2005). Degradation of Rubisco SSU during oxidative stress triggers aggregation of Rubisco particles in Chlamydomonas reinhardtii. Planta 222, 787-793. doi: 10.1007/s00425-005-0023-0

Kornberg, M. D., Sen, N., Hara, M. R., Juluri, K. R., Nguyen, J. V., Snowman, A. M., et al. (2010). GAPDH mediates nitrosylation of nuclear proteins. Nat. Cell Biol. 12, 1094-1100. doi: 10.1038/ncb2114

Latzko, E., Von Garnier, R., and Gibbs, M. (1970). Effect of photosynthesis, photosynthetic inhibitors and oxygen on the activity of ribulose 5-phosphate kinase. Biochem. Biophys. Res. Commun. 39, 1140-1144. doi: 10.1016/0006291X(70)90678-9

Lemaire, M., Schmitter, J. M., Issakidis, E., Miginiac-Maslow, M., Gadal, P., and Decottignies, P. (1994). Essential histidine at the active site of sorghum leaf NADP-dependent malate dehydrogenase. J. Biol. Chem. 269, 27291-27296.

Lemaire, S. D., Collin, V., Keryer, E., Quesada, A., and Miginiac-Maslow, M. (2003). Characterization of thioredoxin y, a new type of thioredoxin identified in the genome of Chlamydomonas reinhardtii. FEBS Lett. 543, 87-92. doi: 10.1016/S0014-5793(03)00416-2

Lemaire, S. D., Guillon, B., Le Maréchal, P., Keryer, E., Miginiac-Maslow, M., and Decottignies, P. (2004). New thioredoxin targets in the unicellular photosynthetic eukaryote Chlamydomonas reinhardtii. Proc. Natl. Acad. Sci. U.S.A. 101, 7475-7480. doi: 10.1073/pnas.0402221101

Lemaire, S. D., Michelet, L., Zaffagnini, M., Massot, V., and Issakidis-Bourguet, E. (2007). Thioredoxins in chloroplasts. Curr. Genet. 51, 343-365. doi: 10.1007/s00294-007-0128-Z

Lemaire, S. D., Quesada, A., Merchan, F., Corral, J. M., Igeno, M. I., Keryer, E., et al. (2005). NADP-malate dehydrogenase from unicellular green alga Chlamydomonas reinhardtii. A first step toward redox regulation? Plant Physiol. 137, 514-521. doi: 10.1104/pp.104.052670

Li, M., Yang, Q., Zhang, L., Li, H., Cui, Y., and Wu, Q. (2007). Identification of novel targets of cyanobacterial glutaredoxin. Arch. Biochem. Biophys. 458, 220-228. doi: 10.1016/j.abb.2006.12.010

Liaud, M. F., Brandt, U., Scherzinger, M., and Cerff, R. (1997). Evolutionary origin of cryptomonad microalgae: two novel chloroplast/cytosol-specific GAPDH genes as potential markers of ancestral endosymbiont and host cell components. J. Mol. Evol. 44(Suppl. 1), S28-S37. doi: 10.1007/PL00000050

Liaud, M. F., Lichtle, C., Apt, K., Martin, W., and Cerff, R. (2000). Compartmentspecific isoforms of TPI and GAPDH are imported into diatom mitochondria as a fusion protein: evidence in favor of a mitochondrial origin of the eukaryotic glycolytic pathway. Mol. Biol. Evol. 17, 213-223. doi: 10.1093/oxfordjournals.molbev.a026301

Lin, A., Wang, Y., Tang, J., Xue, P., Li, C., Liu, L., et al. (2012). Nitric oxide and protein S-nitrosylation are integral to hydrogen peroxide-induced leaf cell death in rice. Plant Physiol. 158, 451-464. doi: 10.1104/pp.111.184531

Lindahl, M., and Florencio, F. J. (2003). Thioredoxin-linked processes in cyanobacteria are as numerous as in chloroplasts, but targets are different. Proc. Natl. Acad. Sci. U.S.A. 100, 16107-16112. doi: 10.1073/pnas. 2534397100

Lindahl, M., and Kieselbach, T. (2009). Disulphide proteomes and interactions with thioredoxin on the track towards understanding redox regulation in chloroplasts and cyanobacteria. J. Proteomics 72, 416-438. doi: 10.1016/j.jprot.2009.01.003

Lindahl, M., Mata-Cabana, A., and Kieselbach, T. (2011). The disulfide proteome and other reactive cysteine proteomes: analysis and functional significance. Antioxid. Redox Signal. 14, 2581-2642. doi: 10.1089/ars.2010.3551

Lindermayr, C., Saalbach, G., and Durner, J. (2005). Proteomic identification of S-nitrosylated proteins in Arabidopsis. Plant Physiol. 137, 921-930. doi: 10.1104/pp.104.058719

Maberly, S. C., Courcelle, C., Groben, R., and Gontero, B. (2010). Phylogenetically-based variation in the regulation of the Calvin cycle enzymes, phosphoribulokinase and glyceraldehyde-3-phosphate dehydrogenase, in algae. J. Exp. Bot. 61, 735-745. doi: 10.1093/jxb/erp337

Maeda, K., Finnie, C., and Svensson, B. (2004). Cy5 maleimide labelling for sensitive detection of free thiols in native protein extracts: identification of seed proteins targeted by barley thioredoxin h isoforms. Biochem. J. 378, 497-507. doi: 10.1042/BJ20031634

Majeran, W., Cai, Y., Sun, Q., and Van Wijk, K. J. (2005). Functional differentiation of bundle sheath and mesophyll maize chloroplasts determined by comparative proteomics. Plant Cell 17, 3111-3140. doi: 10.1105/tpc.105.035519

Marchand, C., Le Marechal, P., Meyer, Y., and Decottignies, P. (2006). Comparative proteomic approaches for the isolation of proteins interacting with thioredoxin. Proteomics 6, 6528-6537. doi: 10.1002/pmic.200600443

Marchand, C., Le Maréchal, P., Meyer, Y., Miginiac-Maslow, M., Issakidis-Bourguet, E., and Decottignies, P. (2004). New targets of Arabidopsis thioredoxins revealed by proteomic analysis. Proteomics 4, 2696-2706. doi: 10.1002/pmic.200400805

Marchand, C. H., Vanacker, H., Collin, V., Issakidis-Bourguet, E., Marechal, P. L., and Decottignies, P. (2010). Thioredoxin targets in Arabidopsis roots. Proteomics 10, 2418-2428. doi: 10.1002/pmic.200900835

Marcus, Y., Altman-Gueta, H., Finkler, A., and Gurevitz, M. (2003). Dual role of cysteine 172 in redox regulation of ribulose 1,5-bisphosphate carboxylase/oxygenase activity and degradation. J. Bacteriol. 185, 1509-1517. doi: 10.1128/JB.185.5.1509-1517.2003

Marin-Navarro, J., and Moreno, J. (2006). Cysteines 449 and 459 modulate the reduction-oxidation conformational changes of ribulose 1.5-bisphosphate carboxylase/oxygenase and the translocation of the enzyme to membranes during stress. Plant Cell Environ. 29, 898-908. doi: 10.1111/j.1365-3040.2005.01469.x

Maron, B. A., Tang, S. S., and Loscalzo, J. (2013). S-nitrosothiols and the Snitrosoproteome of the cardiovascular system. Antioxid. Redox Signal. 18, 270-287. doi: 10.1089/ars.2012.4744

Marri, L., Pesaresi, A., Valerio, C., Lamba, D., Pupillo, P., Trost, P., et al. (2010). In vitro characterization of Arabidopsis CP12 isoforms reveals common biochemical and molecular properties. J. Plant Physiol. 167, 939-950. doi: 10.1016/j.jplph.2010.02.008

Marri, L., Trost, P., Pupillo, P., and Sparla, F. (2005). Reconstitution and properties of the recombinant glyceraldehyde-3-phosphate dehydrogenase/CP12/phosphoribulokinase supramolecular complex of Arabidopsis. Plant Physiol. 139, 1433-1443. doi: 10.1104/pp.105.068445

Marri, L., Trost, P., Trivelli, X., Gonnelli, L., Pupillo, P., and Sparla, F. (2008). Spontaneous assembly of photosynthetic supramolecular complexes as mediated by the intrinsically unstructured protein CP12. J. Biol. Chem. 283, 1831-1838. doi: 10.1074/jbc.M705650200

Marri, L., Zaffagnini, M., Collin, V., Issakidis-Bourguet, E., Lemaire, S. D., Pupillo, P., et al. (2009). Prompt and Easy Activation by Specific Thioredoxins of Calvin Cycle Enzymes of Arabidopsis thaliana Associated in the GAPDH/CP12/PRK Supramolecular Complex. Mol. Plant 2, 259-269. doi: 10.1093/mp/ssn061

Martin, W., Mustafa, A. Z., Henze, K., and Schnarrenberger, C. (1996). Higherplant chloroplast and cytosolic fructose-1,6-bisphosphatase isoenzymes: origins via duplication rather than prokaryote-eukaryote divergence. Plant Mol. Biol. 32, 485-491. doi: 10.1007/BF00019100

Marx, C., Wong, J. H., and Buchanan, B. B. (2003). Thioredoxin and germinating barley: targets and protein redox changes. Planta 216, 454-460. doi 10.1007/s00425-002-0857-7

Matsumura, H., Kai, A., Maeda, T., Tamoi, M., Satoh, A., Tamura, H., et al. (2011). Structure basis for the regulation of glyceraldehyde-3-phosphate dehydrogenase activity via the intrinsically disordered protein CP12. Structure 19, 1846-1854. doi: 10.1016/j.str.2011.08.016

McKinney, D. W., Buchanan, B. B., and Wolosiuk, R. A. (1978). Activation of chloroplast ATPase by reduced thioredoxin. Phytochemistry 17, 794-795. doi: 10.1016/S0031-9422(00)94230-4

McKinney, D. W., Buchanan, B. B., and Wolosiuk, R. A. (1979). Association of a thioredoxin-like protein with chloroplast coupling factor (CF1). Biochem. Biophys. Res. Commun. 86, 1178-1184. doi: 10.1016/0006-291X(79)90241-9

Melandri, B. A., Baccarini, A., and Pupillo, P. (1968). Glyceraldehyde-3-phosphate dehydrogenase in photosynthetic tissues: kinetic evidence for competitivity between NADP and NAD. Biochem. Biophys. Res. Commun. 33, 160-164. doi: 10.1016/0006-291X(68)90272-6

Meng, L., Wong, J. H., Feldman, L. J., Lemaux, P. G., and Buchanan, B. B. (2010). A membrane-associated thioredoxin required for plant growth moves from cell 
to cell, suggestive of a role in intercellular communication. Proc. Natl. Acad. Sci. U.S.A. 107, 3900-3905. doi: 10.1073/pnas.0913759107

Mestres-Ortega, D., and Meyer, Y. (1999). The Arabidopsis thaliana genome encodes at least four thioredoxins $\mathrm{m}$ and a new prokaryotic-like thioredoxin. Gene 240, 307-316. doi: 10.1016/S0378-1119(99)00448-5

Michelet, L., Zaffagnini, M., Marchand, C., Collin, V., Decottignies, P., Tsan, P., et al. (2005). Glutathionylation of chloroplast thioredoxin $\mathrm{f}$ is a redox signaling mechanism in plants. Proc. Natl. Acad. Sci. U.S.A. 102, 16478-16483. doi: 10.1073/pnas.0507498102

Michelet, L., Zaffagnini, M., Massot, V., Keryer, E., Vanacker, H., Miginiac-Maslow, M., et al. (2006). Thioredoxins, glutaredoxins, and glutathionylation: new crosstalks to explore. Photosynth. Res. 89, 225-245. doi: 10.1007/s11120-0069096-2

Michelet, L., Zaffagnini, M., Vanacker, H., Le Marechal, P., Marchand, C., Schroda, M., et al. (2008). In vivo targets of S-thiolation in Chlamydomonas reinhardtii. J. Biol. Chem. 283, 21571-21578. doi: 10.1074/jbc.M802331200

Michels, A. K., Wedel, N., and Kroth, P. G. (2005). Diatom plastids possess a phosphoribulokinase with an altered regulation and no oxidative pentose phosphate pathway. Plant Physiol. 137, 911-920. doi: 10.1104/pp.104.055285

Mieyal, J. J., Gallogly, M. M., Qanungo, S., Sabens, E. A., and Shelton, M. D. (2008). Molecular mechanisms and clinical implications of reversible protein S-glutathionylation. Antioxid. Redox Signal. 10, 1941-1988. doi: 10.1089/ars.2008.2089

Miginiac-Maslow, M., and Lancelin, J. M. (2002). Intrasteric inhibition in redox signalling: light activation of NADP-malate dehydrogenase. Photosynth. Res. 72, 1-12. doi: 10.1023/A:1016099228450

Mikkelsen, R., Mutenda, K. E., Mant, A., Schürmann, P., and Blennow, A. (2005). Alpha-glucan, water dikinase (GWD): a plastidic enzyme with redox-regulated and coordinated catalytic activity and binding affinity. Proc. Natl. Acad. Sci. U.S.A. 102, 1785-1790. doi: 10.1073/pnas.0406674102

Milanez, S., Mural, R. J., and Hartman, F. C. (1991). Roles of cysteinyl residues of phosphoribulokinase as examined by site-directed mutagenesis. J. Biol. Chem. 266, 10694-10699.

Moreno, J., Garcia-Murria, M. J., and Marin-Navarro, J. (2008). Redox modulation of Rubisco conformation and activity through its cysteine residues. J. Exp. Bot. 59, 1605-1614. doi: 10.1093/jxb/erm310

Moreno, J., and Spreitzer, R. J. (1999). C172S substitution in the chloroplastencoded large subunit affects stability and stress-induced turnover of ribulose1,5-bisphosphate carboxylase/oxygenase. J. Biol. Chem. 274, 26789-26793. doi: 10.1074/jbc.274.38.26789

Motohashi, K., and Hisabori, T. (2006). HCF164 receives the reducing equivalents from stroma thioredoxin across thylakoid membrane and mediates reduction of target proteins in thylakoid lumen. J Biol Chem. doi: 10.1074/jbc.M605938200

Motohashi, K., and Hisabori, T. (2010). CcdA is a thylakoid membrane protein required for the transfer of reducing equivalents from stroma to thylakoid lumen in the higher plant chloroplast. Antioxid. Redox Signal. 13, 1169-1176. doi: 10.1089/ars.2010.3138

Motohashi, K., Kondoh, A., Stumpp, M. T., and Hisabori, T. (2001). Comprehensive survey of proteins targeted by chloroplast thioredoxin. Proc. Natl. Acad. Sci. U.S.A. 98, 11224-11229. doi: 10.1073/pnas.191282098

Mueller-Cajar, O., Stotz, M., and Bracher, A. (2013). Maintaining photosynthetic CO2 fixation via protein remodelling: the Rubisco activases. Photosynth. Res. in press. doi: 10.1007/s11120-013-9819-0

Muthuramalingam, M., Matros, A., Scheibe, R., Mock, H. P., and Dietz, K. J. (2013). The hydrogen peroxide-sensitive proteome of the chloroplast in vitro and in vivo. Front Plant. Sci. 4:54. doi: 10.3389/fpls.2013.00054

Navrot, N., Gelhaye, E., Jacquot, J. P., and Rouhier, N. (2006). Identification of a new family of plant proteins loosely related to glutaredoxins with four CxxC motives. Photosynth. Res. 89, 71-79. doi: 10.1007/s11120-006-9083-7

Nee, G., Zaffagnini, M., Trost, P., and Issakidis-Bourguet, E. (2009). Redox regulation of chloroplastic glucose-6-phosphate dehydrogenase: a new role for f-type thioredoxin. FEBS Lett. 583, 2827-2832. doi: 10.1016/j.febslet.2009.07.035

Nicholson, S., Easterby, J. S., and Powls, R. (1987). Properties of a multimeric protein complex from chloroplasts possessing potential activities of NADPHdependent glyceraldehyde-3-phosphate dehydrogenase and phosphoribulokinase. Eur. J. Biochem. 162, 423-431. doi: 10.1111/j.1432-1033.1987.tb10619.x

Nishizawa, A. N., and Buchanan, B. B. (1981). Enzyme regulation in C4 photosynthesis. Purification and properties of thioredoxin-linked fructose bisphosphatase and sedoheptulose bisphosphatase from corn leaves. J. Biol. Chem. 256, 6119-6126.

Noctor, G., Mhamdi, A., Chaouch, S., Han, Y., Neukermans, J., Marquez-Garcia, B., et al. (2012). Glutathione in plants: an integrated overview. Plant Cell Environ. 35, 454-484. doi: 10.1111/j.1365-3040.2011.02400.x

O’brien, M. J., Easterby, J. S., and Powls, R. (1976). Algal glyceraldehyde3-phosphate dehydrogenases. Conversion of the NADH-linked enzyme of Scenedesmus obliquus into a form which preferentially uses NADPH as coenzyme. Biochim. Biophys. Acta 449, 209-223. doi: 10.1016/0005-2728(76)90134-1

Ocheretina, O., Haferkamp, I., Tellioglu, H., and Scheibe, R. (2000). Lightmodulated NADP-malate dehydrogenases from mossfern and green algae: insights into evolution of the enzyme's regulation. Gene 258, 147-154. doi: 10.1016/S0378-1119(00)00409-1

Pedersen, T. A., Kirk, M., and Bassham, J. A. (1966). Light-dark transients in levels of intermediate compounds during photosynthesis in air-adapted Chlorella. Physiol. Plant 19, 219-231. doi: 10.1111/j.1399-3054.1966.tb09094.x

Pérez-Pérez, M. E., Florencio, F. J., and Lindahl, M. (2006). Selecting thioredoxins for disulphide proteomics: target proteomes of three thioredoxins from the cyanobacterium Synechocystis sp. PCC 6803. Proteomics 6(Suppl. 1), S186-S195. doi: 10.1002/pmic.200500215

Pérez-Pérez, M. E., Martin-Figueroa, E., and Florencio, F. J. (2009). Photosynthetic regulation of the cyanobacterium Synechocystis sp. PCC 6803 thioredoxin system and functional analysis of $\operatorname{TrxB}(\operatorname{Trx} \mathrm{x})$ and $\operatorname{Tr} \mathrm{QQ}(\operatorname{Trx} \mathrm{y})$ thioredoxins. Mol. Plant 2, 270-283. doi: 10.1093/mp/ssn070

Petersen, J., Teich, R., Becker, B., Cerff, R., and Brinkmann, H. (2006). The GapA/B gene duplication marks the origin of Streptophyta (charophytes and land plants). Mol. Biol. Evol. 23, 1109-1118. doi: 10.1093/molbev/msj123

Pfannschmidt, T., and Yang, C. (2012). The hidden function of photosynthesis: a sensing system for environmental conditions that regulates plant acclimation responses. Protoplasma 249(Suppl. 2), S125-S136. doi: 10.1007/s00709-0120398-2

Pohlmeyer, K., Paap, B. K., Soll, J., and Wedel, N. (1996). CP12: a small nuclearencoded chloroplast protein provides novel insights into higher-plant GAPDH evolution. Plant Mol. Biol. 32, 969-978. doi: 10.1007/BF00020493

Porter, M. A., and Hartman, F. C. (1988). Catalytic nonessentiality of an active-site cysteinyl residue of phosphoribulokinase. J. Biol. Chem. 263, 14846-14849.

Porter, M. A., and Hartman, F. C. (1990). Exploration of the function of a regulatory sulfhydryl of phosphoribulokinase from spinach. Arch. Biochem. Biophys. 281, 330-334. doi: 10.1016/0003-9861(90)90452-5

Porter, M. A., Milanez, S., Stringer, C. D., and Hartman, F. C. (1986). Purification and characterization of ribulose-5-phosphate kinase from spinach. Arch. Biochem. Biophys. 245, 14-23. doi: 10.1016/0003-9861(86)90185-2

Portis, A. R. Jr. (2003). Rubisco activase - Rubisco's catalytic chaperone. Photosynth. Res. 75, 11-27. doi: 10.1023/A:1022458108678

Portis, A. R. Jr., Li, C., Wang, D., and Salvucci, M. E. (2008). Regulation of Rubisco activase and its interaction with Rubisco. J. Exp. Bot. 59, 1597-1604. doi: 10.1093/jxb/erm240

Pupillo, P., and Piccari, G. G. (1973). The effect of NADP on the subunit structure and activity of spinach chloroplast glyceraldehyde-3-phosphate dehydrogenase. Arch. Biochem. Biophys. 154, 324-331. doi: 10.1016/0003-9861(73)90064-7

Raines, C. A., Lloyd, J. C., Willingham, N. M., Potts, S., and Dyer, T. A. (1992). cDNA and gene sequences of wheat chloroplast sedoheptulose-1,7bisphosphatase reveal homology with fructose-1,6-bisphosphatases. Eur. J. Biochem. 205, 1053-1059. doi: 10.1111/j.1432-1033.1992.tb16873.x

Rey, P., Cuine, S., Eymery, F., Garin, J., Court, M., Jacquot, J. P., et al. (2005). Analysis of the proteins targeted by CDSP32, a plastidic thioredoxin participating in oxidative stress responses. Plant J. 41, 31-42. doi: 10.1111/j.1365313X.2004.02271.x

Rivas, S., Rougon-Cardoso, A., Smoker, M., Schauser, L., Yoshioka, H., and Jones, J. D. (2004). CITRX thioredoxin interacts with the tomato Cf-9 resistance protein and negatively regulates defence. EMBO J. 23, 2156-2165. doi: 10.1038/sj.emboj.7600224

Robbens, S., Petersen, J., Brinkmann, H., Rouze, P., and Van De Peer, Y. (2007). Unique regulation of the Calvin cycle in the ultrasmall green alga Ostreococcus. J. Mol. Evol. 64, 601-604. doi: 10.1007/s00239-006-0159-y

Rodriguez-Pascual, F., Redondo-Horcajo, M., Magan-Marchal, N., Lagares, D., Martinez-Ruiz, A., Kleinert, H., et al. (2008). Glyceraldehyde-3-phosphate dehydrogenase regulates endothelin-1 expression by a novel, redox-sensitive 
mechanism involving mRNA stability. Mol. Cell Biol. 28, 7139-7155. doi: 10.1128/MCB.01145-08

Rodriguez-Suarez, R. J., Mora-Garcia, S., and Wolosiuk, R. A. (1997). Characterization of cysteine residues involved in the reductive activation and the structural stability of rapeseed (Brassica napus) chloroplast fructose1,6-bisphosphatase. Biochem. Biophys. Res. Commun. 232, 388-393. doi: 10.1006/bbrc. 1997.6242

Romero-Puertas, M. C., Campostrini, N., Matte, A., Righetti, P. G., Perazzolli, M., Zolla, L., et al. (2008). Proteomic analysis of S-nitrosylated proteins in Arabidopsis thaliana undergoing hypersensitive response. Proteomics 8, 1459-1469. doi: 10.1002/pmic.200700536

Rouhier, N., Lemaire, S. D., and Jacquot, J. P. (2008). The role of glutathione in photosynthetic organisms: emerging functions for glutaredoxins and glutathionylation. Annu. Rev. Plant Biol. 59, 143-166. doi: 10.1146/annurev.arplant.59.032607.092811

Rouhier, N., Villarejo, A., Srivastava, M., Gelhaye, E., Keech, O., Droux, M., et al. (2005). Identification of plant glutaredoxin targets. Antioxid. Redox Signal. 7, 919-929. doi: 10.1089/ars.2005.7.919

Ruelland, E., Lemaire-Chamley, M., Le Maréchal, P., Issakidis-Bourguet, E., Djukic, N., and Miginiac-Maslow, M. (1997). An internal cysteine is involved in the thioredoxin-dependent activation of sorghum leaf NADP-malate dehydrogenase. J. Biol. Chem. 272, 19851-19857. doi: 10.1074/jbc.272.32.19851

Ruelland, E., and Miginiac-Maslow, M. (1999). Regulation of chloroplast enzyme activities by thioredoxins: activation or relief from inhibition? Trends Plant. Sci. 4, 136-141. doi: 10.1016/S1360-1385(99)01391-6

Salvucci, M. E., Van De Loo, F. J., and Stecher, D. (2003). Two isoforms of Rubisco activase in cotton, the products of separate genes not alternative splicing. Planta 216, 736-744. doi: 10.1007/s00425-002-0923-1

Salvucci, M. E., Werneke, J. M., Ogren, W. L., and Portis, A. R. (1987). Purification and species distribution of rubisco activase. Plant Physiol. 84, 930-936. doi: 10.1104/pp.84.3.930

Scagliarini, S., Trost, P., Pupillo, P., and Valenti, V. (1993). Light activation and molecular-mass changes of $\mathrm{NAD}(\mathrm{P})$-glyceraldehyde 3-phosphate dehydrogenase of spinach and maize leaves. Planta 190, 313-319. doi: 10.1007/BF00196959

Scheibe, R. (2004). Malate valves to balance cellular energy supply. Physiol. Plant 120, 21-26. doi: 10.1111/j.0031-9317.2004.0222.x

Scheibe, R., and Dietz, K. J. (2012). Reduction-oxidation network for flexible adjustment of cellular metabolism in photoautotrophic cells. Plant Cell Environ. 35, 202-216. doi: 10.1111/j.1365-3040.2011.02319.x

Scheibe, R., Wedel, N., Vetter, S., Emmerlich, V., and Sauermann, S. M. (2002). Co-existence of two regulatory NADP-glyceraldehyde 3-P dehydrogenase complexes in higher plant chloroplasts. Eur. J. Biochem. 269, 5617-5624. doi: 10.1046/j.1432-1033.2002.03269.x

Schroter, Y., Steiner, S., Matthai, K., and Pfannschmidt, T. (2010). Analysis of oligomeric protein complexes in the chloroplast sub-proteome of nucleic acid-binding proteins from mustard reveals potential redox regulators of plastid gene expression. Proteomics 10, 2191-2204. doi: 10.1002/pmic. 200900678

Schürmann, P., and Buchanan, B. B. (1975). Role of ferredoxin in the activation of sedoheptulose diphosphatase in isolated chloroplasts. Biochim. Biophys. Acta 376, 189-192. doi: 10.1016/0005-2728(75)90217-0

Schürmann, P., and Buchanan, B. B. (2008). The ferredoxin/thioredoxin system of oxygenic photosynthesis. Antioxid. Redox Signal. 10, 1235-1274. doi: 10.1089/ars.2007.1931

Schürmann, P., and Jacquot, J. P. (2000). Plant thioredoxin systems revisited. Annu. Rev. Plant Physiol. Plant. Mol. Biol. 51, 371-400. doi: 10.1146/annurev.arplant.51.1.371

Sengupta, R., and Holmgren, A. (2013). Thioredoxin and thioredoxin reductase in relation to reversible s-nitrosylation. Antioxid. Redox Signal. 18, 259-269. doi: 10.1089/ars.2012.4716

Sparla, F., Costa, A., Lo Schiavo, F., Pupillo, P., and Trost, P. (2006). Redox regulation of a novel plastid-targeted beta-amylase of Arabidopsis. Plant Physiol. 141, 840-850. doi: 10.1104/pp.106.079186

Sparla, F., Pupillo, P., and Trost, P. (2002). The C-terminal extension of glyceraldehyde-3-phosphate dehydrogenase subunit B acts as an autoinhibitory domain regulated by thioredoxins and nicotinamide adenine dinucleotide. J. Biol. Chem. 277, 44946-44952. doi: 10.1074/jbc. M206873200
Sparla, F., Zaffagnini, M., Wedel, N., Scheibe, R., Pupillo, P., and Trost, P. (2005). Regulation of photosynthetic GAPDH dissected by mutants. Plant Physiol. 138, 2210-2219. doi: 10.1104/pp.105.062117

Stanley, D. N., Raines, C. A., and Kerfeld, C. A. (2013). Comparative analysis of 126 cyanobacterial genomes reveals evidence of functional diversity among homologs of the redox-regulated CP12 protein. Plant Physiol. 161, 824-835. doi: 10.1104/pp.112.210542

Stotz, M., Mueller-Cajar, O., Ciniawsky, S., Wendler, P., Hartl, F. U., Bracher, A., et al. (2011). Structure of green-type Rubisco activase from tobacco. Nat. Struct. Mol. Biol. 18, 1366-1370. doi: 10.1038/nsmb.2171

Tamoi, M., Ishikawa, T., Takeda, T., and Shigeoka, S. (1996). Molecular characterization and resistance to hydrogen peroxide of two fructose-1,6-bisphosphatases from Synechococcus PCC 7942. Arch. Biochem. Biophys. 334, 27-36. doi: 10.1006/abbi.1996.0425

Tamoi, M., Miyazaki, T., Fukamizo, T., and Shigeoka, S. (2005). The Calvin cycle in cyanobacteria is regulated by $\mathrm{CP} 12$ via the $\mathrm{NAD}(\mathrm{H}) / \mathrm{NADP}(\mathrm{H})$ ratio under light/dark conditions. Plant J. 42, 504-513. doi: 10.1111/j.1365313X.2005.02391.x

Tanou, G., Filippou, P., Belghazi, M., Job, D., Diamantidis, G., Fotopoulos, V., et al. (2012). Oxidative and nitrosative-based signaling and associated posttranslational modifications orchestrate the acclimation of citrus plants to salinity stress. Plant J. 72, 585-599. doi: 10.1111/j.1365-313X.2012.05100.x

Tanou, G., Job, C., Rajjou, L., Arc, E., Belghazi, M., Diamantidis, G., et al. (2009). Proteomics reveals the overlapping roles of hydrogen peroxide and nitric oxide in the acclimation of citrus plants to salinity. Plant J. 60, 795-804. doi: 10.1111/j.1365-313X.2009.04000.x

Tarrago, L., Laugier, E., Zaffagnini, M., Marchand, C., Le Marechal, P., Rouhier, N., et al. (2009). Regeneration mechanisms of Arabidopsis thaliana methionine sulfoxide reductases B by glutaredoxins and thioredoxins. J. Biol. Chem. 284, 18963-18971. doi: 10.1074/jbc.M109.015487

Tarrago, L., Laugier, E., Zaffagnini, M., Marchand, C. H., Le Marechal, P., Lemaire, S. D., et al. (2010). Plant thioredoxin CDSP32 regenerates 1-cys methionine sulfoxide reductase B activity through the direct reduction of sulfenic acid. J. Biol. Chem. 285, 14964-14972. doi: 10.1074/jbc.M110.108373

Terauchi, A. M., Lu, S. F., Zaffagnini, M., Tappa, S., Hirasawa, M., Tripathy, J. N., et al. (2009). Pattern of expression and substrate specificity of chloroplast ferredoxins from Chlamydomonas reinhardtii. J. Biol. Chem. 284, 25867-25878. doi: 10.1074/jbc.M109.023622

Thompson, L. R., Zeng, Q., Kelly, L., Huang, K. H., Singer, A. U., Stubbe, J., et al. (2011). Phage auxiliary metabolic genes and the redirection of cyanobacterial host carbon metabolism. Proc. Natl. Acad. Sci. U.S.A. 108, E757-E764. doi: 10.1073/pnas.1102164108

Trost, P., Fermani, S., Marri, L., Zaffagnini, M., Falini, G., Scagliarini, S., et al. (2006). Thioredoxin-dependent regulation of photosynthetic glyceraldehyde3-phosphate dehydrogenase: autonomous vs. CP12-dependent mechanisms. Photosynth. Res. 89, 263-275. doi: 10.1007/s11120-006-9099-Z

Trost, P., Scagliarini, S., Valenti, V., and Pupillo, P. (1993). Activation of spinach chloroplast glyceraldehyde 3-phosphate dehydrogenase. Effect of glycerate 1,3-bisphosphate. Planta 190, 320-326. doi: 10.1007/ BF00196960

Tsukamoto, Y., Fukushima, Y., Hara, S., and Hisabori, T. (2013). Redox control of the activity of phosphoglycerate kinase in Synechocystis sp. PCC6803. Plant Cell Physiol. 54, 484-491. doi: 10.1093/pcp/pct002

Uniacke, J., and Zerges, W. (2008). Stress induces the assembly of RNA granules in the chloroplast of Chlamydomonas reinhardtii. J. Cell Biol. 182, 641-646. doi: $10.1083 /$ jcb. 200805125

Vescovi, M., Zaffagnini, M., Festa, M., Trost, P., Lo Schiavo, F., and Costa, A. (2013). Nuclear accumulation of cytosolic glyceraldehyde-3-phosphate dehydrogenase in cadmium-stressed Arabidopsis roots. Plant Physiol. 162, 333-346. doi: 10.1104/pp.113.215194

Villeret, V., Huang, S., Zhang, Y., Xue, Y., and Lipscomb, W. N. (1995). Crystal structure of spinach chloroplast fructose-1,6-bisphosphatase at 2.8 A resolution. Biochemistry 34, 4299-4306. doi: 10.1021/bi00013a019

Wadano, A., Nishikawa, K., Hirahashi, T., Satoh, R., and Iwaki, T. (1998). Reaction mechanism of phosphoribulokinase from a cyanobacterium, Synechococcus PCC7942. Photosynth. Res. 56, 27-33. doi: 10.1023/A:1005979801741

Wang, D., and Portis, A. R., Jr. (2006). Increased sensitivity of oxidized large isoform of ribulose-1,5-bisphosphate carboxylase/oxygenase (rubisco) activase to ADP inhibition is due to an interaction between its carboxyl 
extension and nucleotide-binding pocket. J. Biol. Chem. 281, 25241-25249. doi: 10.1074/jbc.M604756200

Wara-Aswapati, O., Kemble, R. J., and Bradbeer, J. W. (1980). Activation of Glyceraldehyde-Phosphate Dehydrogenase (NADP) and Phosphoribulokinase in Phaseolus vulgaris Leaf Extracts Involves the Dissociation of Oligomers. Plant Physiol. 66, 34-39. doi: 10.1104/pp.66.1.34

Wedel, N., and Soll, J. (1998). Evolutionary conserved light regulation of Calvin cycle activity by NADPH-mediated reversible phosphoribulokinase/CP12/ glyceraldehyde-3-phosphate dehydrogenase complex dissociation. Proc. Natl. Acad. Sci. U.S.A. 95, 9699-9704. doi: 10.1073/pnas.95.16.9699

Wedel, N., Soll, J., and Paap, B. K. (1997). CP12 provides a new mode of light regulation of Calvin cycle activity in higher plants. Proc. Natl. Acad. Sci. U.S.A. 94, 10479-10484. doi: 10.1073/pnas.94.19.10479

Wenderoth, I., Scheibe, R., and Von Schaewen, A. (1997). Identification of the cysteine residues involved in redox modification of plant plastidic glucose-6-phosphate dehydrogenase. J. Biol. Chem. 272, 26985-26990. doi: 10.1074/jbc.272.43.26985

Werneke, J. M., and Ogren, W. L. (1989). Structure of an Arabidopsis thaliana cDNA encoding rubisco activase. Nucleic Acids Res. 17, 2871. doi: 10.1093/nar/17.7.2871

Winkler, M., Hemschemeier, A., Jacobs, J., Stripp, S., and Happe, T. (2010). Multiple ferredoxin isoforms in Chlamydomonas reinhardtii - their role under stress conditions and biotechnological implications. Eur J. Cell Biol. 89, 998-1004. doi: 10.1016/j.ejcb.2010.06.018

Wolosiuk, R. A., and Buchanan, B. B. (1976). Studies on the regulation of chloroplast NADP-linked glyceraldehyde-3-phosphate dehydrogenase. J. Biol. Chem. 251, 6456-6461.

Wolosiuk, R. A., and Buchanan, B. B. (1978a). Activation of Chloroplast NADP-linked Glyceraldehyde-3-Phosphate Dehydrogenase by the Ferredoxin/Thioredoxin System. Plant Physiol. 61, 669-671. doi: 10.1104/pp.61.4.669

Wolosiuk, R. A., and Buchanan, B. B. (1978b). Regulation of chloroplast phosphoribulokinase by the ferredoxin/thioredoxin system. Arch. Biochem. Biophys. 189, 97-101. doi: 10.1016/0003-9861(78)90119-4

Wolosiuk, R. A., Crawford, N. A., Yee, B. C., and Buchanan, B. B. (1979). Isolation of three thioredoxins from spinach leaves. J. Biol. Chem. 254, 1627-1632.

Wong, J. H., Balmer, Y., Cai, N., Tanaka, C. K., Vensel, W. H., Hurkman, W. J., et al. (2003). Unraveling thioredoxin-linked metabolic processes of cereal starchy endosperm using proteomics. FEBS Lett. 547, 151-156. doi: 10.1016/S00145793(03)00696-3

Wong, J. H., Cai, N., Balmer, Y., Tanaka, C. K., Vensel, W. H., Hurkman, W. J., et al. (2004). Thioredoxin targets of developing wheat seeds identified by complementary proteomic approaches. Phytochemistry 65, 1629-1640. doi: 10.1016/j.phytochem.2004.05.010

Yamazaki, D., Motohashi, K., Kasama, T., Hara, Y., and Hisabori, T. (2004). Target proteins of the cytosolic thioredoxins in Arabidopsis thaliana. Plant Cell Physiol. 45, 18-27. doi: 10.1093/pcp/pch019

Yano, H., and Kuroda, M. (2006). Disulfide proteome yields a detailed understanding of redox regulations: a model study of thioredoxin-linked reactions in seed germination. Proteomics 6, 294-300. doi: 10.1002/pmic.200402033

Yano, H., Wong, J. H., Lee, Y. M., Cho, M. J., and Buchanan, B. B. (2001). A strategy for the identification of proteins targeted by thioredoxin. Proc. Natl. Acad. Sci. U.S.A. 98, 4794-4799. doi: 10.1073/pnas.071041998

Yin, Z., Meng, F., Song, H., Wang, X., Xu, X., and Yu, D. (2010). Expression quantitative trait loci analysis of two genes encoding rubisco activase in soybean. Plant Physiol. 152, 1625-1637. doi: 10.1104/pp.109.148312

Yosef, I., Irihimovitch, V., Knopf, J. A., Cohen, I., Orr-Dahan, I., Nahum, E., et al. (2004). RNA binding activity of the ribulose-1,5-bisphosphate carboxylase/oxygenase large subunit from Chlamydomonas reinhardtii. J. Biol. Chem. 279, 10148-10156. doi: 10.1074/jbc.M308602200
Zaffagnini, M., Bedhomme, M., Groni, H., Marchand, C. H., Puppo, C., Gontero, B., et al. (2012a). Glutathionylation in the photosynthetic model organism Chlamydomonas reinhardtii: a proteomic survey. Mol. Cell Proteomics 11, M111.014142. doi: 10.1074/mcp.M111.014142

Zaffagnini, M., Bedhomme, M., Lemaire, S. D., and Trost, P. (2012b). The emerging roles of protein glutathionylation in chloroplasts. Plant. Sci. 185-186, 86-96. doi: 10.1016/j.plantsci.2012.01.005

Zaffagnini, M., Bedhomme, M., Marchand, C. H., Morisse, S., Trost, P., and Lemaire, S. D. (2012c). Redox regulation in photosynthetic organisms: focus on glutathionylation. Antioxid. Redox Signal. 16, 567-586. doi: $10.1089 /$ ars.2011.4255

Zaffagnini, M., Michelet, L., Marchand, C., Sparla, F., Decottignies, P., Le Marechal, P., et al. (2007). The thioredoxin-independent isoform of chloroplastic glyceraldehyde-3-phosphate dehydrogenase is selectively regulated by glutathionylation. FEBS J. 274, 212-226. doi: 10.1111/j.1742-4658.2006. 05577.x

Zaffagnini, M., Michelet, L., Massot, V., Trost, P., and Lemaire, S. D. (2008). Biochemical characterization of glutaredoxins from Chlamydomonas reinhardtii reveals the unique properties of a chloroplastic CGFStype glutaredoxin. J. Biol. Chem. 283, 8868-8876. doi: 10.1074/jbc. M709567200

Zaffagnini, M., Michelet, L., Sciabolini, C., Di Giacinto, N., Morisse, S., Marchand, C. H., et al. (2013a). High-resolution crystal structure and redox properties of chloroplastic triosephosphate isomerase from Chlamydomonas reinhardtii. Mol. Plant. doi: 10.1093/mp/sst139. [Epub ahead of print].

Zaffagnini, M., Morisse, S., Bedhomme, M., Marchand, C. H., Festa, M., Rouhier, N., et al. (2013b). Mechanism of nitrosylation and denitrosylation of cytosolic glyceraldehyde-3-phosphate dehydrogenase from Arabidopsis. J. Biol. Chem. 288, 22777-22789. doi: 10.1074/jbc.M113.475467

Zhang, N., Schürmann, P., and Portis, A. R. Jr. (2001). Characterization of the regulatory function of the $46-\mathrm{kDa}$ isoform of Rubisco activase from Arabidopsis. Photosynth. Res. 68, 29-37. doi: 10.1023/A:1011845 506196

Ziegler, H., and Ziegler, I. (1965). Der Einfluss der Belichtung auf Die NADP+Abhängige Glycerinaldehyd-3-Phosphat-Dehydrogenase. Planta 65, 369-380. doi: $10.1007 / \mathrm{BF} 00385415$

Ziegler, H., and Ziegler, I. (1966). Die lichtinduzierte synthese der NADP+abhängigen Glycerinaldehyd-3-Phosphat-Dehydrogenase. Planta 69, 111-123. doi: $10.1007 / B F 00399782$

Conflict of Interest Statement: The authors declare that the research was conducted in the absence of any commercial or financial relationships that could be construed as a potential conflict of interest.

Received: 18 September 2013; accepted: 30 October 2013; published online: 25 November 2013.

Citation: Michelet L, Zaffagnini M, Morisse S, Sparla F, Pérez-Pérez ME, Francia F, Danon A, Marchand CH, Fermani S, Trost P, and Lemaire SD (2013) Redox regulation of the Calvin-Benson cycle: something old, something new. Front. Plant Sci. 4:470. doi: 10.3389/fpls.2013.00470

This article was submitted to Plant Physiology, a section of the journal Frontiers in Plant Science.

Copyright () 2013 Michelet, Zaffagnini, Morisse, Sparla, Pérez-Pérez, Francia, Danon, Marchand, Fermani, Trost, and Lemaire. This is an open-access article distributed under the terms of the Creative Commons Attribution License (CC BY). The use, distribution or reproduction in other forums is permitted, provided the original author(s) or licensor are credited and that the original publication in this journal is cited, in accordance with accepted academic practice. No use, distribution or reproduction is permitted which does not comply with these terms. 